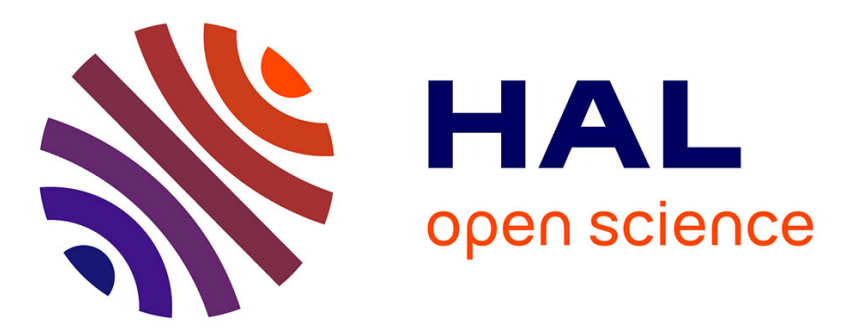

\title{
Social Interactions and Malaria Preventive Behaviors in Sub-Saharan Africa
}

Bénédicte Apouey, Gabriel Picone

\section{To cite this version:}

Bénédicte Apouey, Gabriel Picone. Social Interactions and Malaria Preventive Behaviors in SubSaharan Africa. 2014. halshs-00940084

\section{HAL Id: halshs-00940084 \\ https://shs.hal.science/halshs-00940084}

Preprint submitted on 31 Jan 2014

HAL is a multi-disciplinary open access archive for the deposit and dissemination of scientific research documents, whether they are published or not. The documents may come from teaching and research institutions in France or abroad, or from public or private research centers.
L'archive ouverte pluridisciplinaire HAL, est destinée au dépôt et à la diffusion de documents scientifiques de niveau recherche, publiés ou non, émanant des établissements d'enseignement et de recherche français ou étrangers, des laboratoires publics ou privés. 
WORKING PAPER N²014 - 04

Social Interactions and Malaria Preventive Behaviors in Sub-Saharan Africa

\author{
Bénédicte H. Apouey
}

Gabriel Picone

JEL Codes: I12

Keywords: Social interactions, Social multiplier, Malaria preventive behavior

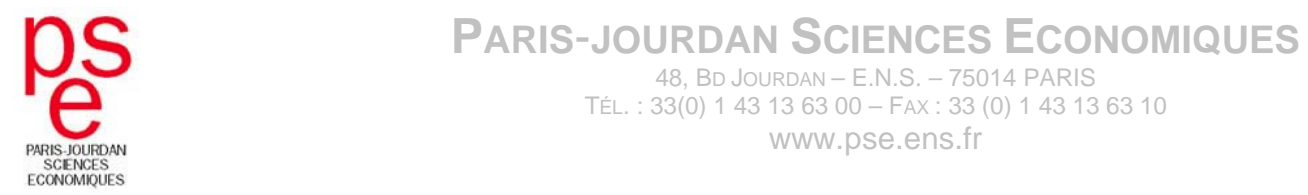




\title{
Social Interactions and Malaria Preventive Behaviors
}

\author{
in Sub-Saharan Africa
}

\author{
BÉNÉDICTE APOUEY ${ }^{\dagger}$ \\ GABRiEl PiCONE ${ }^{\ddagger}$
}

January 29, 2014

\begin{abstract}
This paper examines the existence of social interactions in malaria preventive behaviors in Sub-Saharan Africa, i.e. whether an individual's social environment has an influence on the individual's preventive behaviors. We focus on the two population groups which are the most vulnerable to malaria (children under 5 and pregnant women) and on two preventive behaviors (sleeping under a bednet and taking intermittent preventive treatment during pregnancy). We define the social environment of the individual as people living in the same region. To detect social interactions, we calculate the size of the social multiplier by comparing the effects of an exogenous variable at the individual level and at the regional level. Our data come from 92 surveys for 29 Sub-Saharan countries between 1999 and 2012, and they cover approximately 660,000 children and 95,000 women. Our results indicate that social interactions are important in malaria preventive behaviors, since the social multipliers for women's education and household wealth are greater than one - which means that education and wealth generates larger effects on preventive behaviors in the long run than we would expect from the individual-level specifications, once we account for social interactions.
\end{abstract}

Key words: social interactions, social multiplier, malaria preventive behavior JEL Classification: I12

\footnotetext{
${ }^{\dagger}$ Paris School of Economics - CNRS, 48 Boulevard Jourdan, 75014 Paris, France. Phone: +33-1-4313-63-07. Fax: +33-1-43-13-63-55. E-mail: benedicte.apouey@psemail.eu.

${ }^{\ddagger}$ Corresponding author. University of South Florida, Department of Economics, 4202 E. Fowler Avenue, CMC206A, Tampa, FL 33620-5500, USA. Phone: +1-813-974-6537. Fax: +1-813-974-6510. E-mail: gpicone@usf.edu.
} 


\section{INTRODUCTION}

Malaria is transmitted to people through the bites of infected anopheles mosquitoes. The World Malaria Report estimates that 660,000 individuals died of malaria in 2010. Over $80 \%$ of these deaths occurred in 14 countries in Sub-Saharan Africa and $86 \%$ of them occurred in children under 5 (WHO, 2012). Young children and pregnant women are particularly at risk because they do not have functional immunity against the disease or they temporarily lose their immunity. Fortunately, technologies exist that can prevent and cure malaria. Among these technologies, sleeping under an insecticide-treated net (ITN) is considered one of most effective ways to prevent malaria, since the mosquito dies immediately when it comes into contact with the net. This not only prevents the bite, but also reduces the mosquito population (RBM, 2010). In a comprehensive review of the literature, Lengeler (2004) concludes that widespread use of ITNs could reduce child mortality by $20 \%$. ITNs have also been shown to be cost effective compared to other preventive measures (Binka et al., 1996; Goodman and Mills, 1999; Wiseman et al., 2003). For pregnant women, taking an intermittent preventive treatment (IPTp) during the gestation period has been found very effective in protecting mother and unborn baby from malaria.

In this paper, we empirically analyze the importance of social interactions on these two malaria preventive behaviors (bednet usage and preventive treatment during pregnancy) for children under 5 and pregnant women in Sub-Saharan Africa. Social interactions refer to the influence of the neighbors' preventive behaviors on the individual's preventive behaviors (endogenous social interactions) and to the effect of the neighbors' characteristics on the individual's preventive behavior (exogenous social interactions). Previous studies show that social interactions are important determinants of a wide range of behaviors, including crime (Glaeser et al., 1996), labor force participation (Bernheim, 1994), hybrid corn adoption (Ellison and Fudenberg, 1993), new agricultural technologies adoption (Conley and Udry, 2010), obesity (Auld, 2011), and fertility in developing countries (Canning et al., 2013). But to our knowledge, there is no empirical evidence regarding the existence of social interactions for malaria preventive behaviors. Yet, social interactions 
may be important determinants of the adoption of malaria preventive methods for two reasons. First, mothers and pregnant women may learn about the benefits of malaria preventive behaviors from their neighbors' experiences with bednets or preventive treatments during pregnancy, either through conversation or direct observation (social learning). Second, it is possible that there are social influences from a few sophisticated agents to the rest of the group through explicit or implicit group pressures, where for example sleeping under a bednet becomes the new social norm. ${ }^{1}$

As originally discussed by Manski (1993) and more recently by Blume et al. (2011), it is impossible to identify endogenous and exogenous social interactions separately without longitudinal data containing detailed information on both the individual sources of information and their social networks. Our goal is more modest: we try to identify the existence of social interactions and to calculate the magnitude of the social multiplier implied by these social interactions. The existence of social interactions and the size of the social multiplier have important health policy implications. If there are social interactions, then policies that successfully convince an individual to adopt a technology (such as ITNs) will have a much larger effect in the long run than in the absence of social spillovers. In addition, knowledge about the size of the social multipliers associated with particular explanatory variables will allow policy makers to use resources more efficiently.

To estimate the social multiplier, we follow the strategy developed by Glaeser and Scheinkman (2002), Graham and Hahn (2005), Auld (2011), and Canning et al. (2013). Specifically, we define the neighbors of an individual as the individuals living in his region, and we calculate the size of the social multiplier by comparing the effect of a factor on preventive behaviors at the individual level, with the effect of (the mean of) the factor on (the average) preventive behaviors at the regional level. In the absence of social interactions, the effect of the factor on preventive behaviors at the individual level should be equal to the effect at the regional level. In contrast, we can conclude that there are social interactions if the effect of the factor on preventive behaviors at the regional level

\footnotetext{
${ }^{1}$ The previous economic literature on malaria preventive behaviors studies the role of free distribution and cost sharing on bednets demand and usage (Dupas and Cohen, 2008), tests whether the demand for bednets varies with the framing of the marketing message in Kenya (Dupas, 2009), and quantifies the elasticity of bednet usage with respect to malaria prevalence in Sub-Saharan Africa (Picone et al., 2013).
} 
is greater than at the individual level.

Our method requires repeated cross-sectional data and a large sample size. Our data come from 29 Sub-Saharan countries and 92 surveys (Demographic Health Surveys, Malaria Indicator Surveys, Multiple Indicator Cluster Surveys and AIDS Indicator Survey) between 1999 and 2012.

We find that the effects of women's education and household wealth on preventive behaviors at the regional level are significantly greater than at the individual level. The results provide support for the hypothesis that social interactions play an important role in explaining malaria preventive behaviors. In addition, policies that increase the level of education and wealth are likely to generate larger spillovers than policies that only concentrate on net distribution and preventive treatment uptake.

The paper is organized as follows. Section 2 presents a model of social interactions for malaria preventive behaviors. Section 3 contains the econometric strategy. Section 4 presents the data used in the analysis. Section 5 contains the empirical specification. Section 6 presents our results on the role of social interactions in malaria preventive behaviors, whereas Section 7 contains robustness checks and additional results. Lastly, Section 8 offers some concluding remarks.

\section{A MODEL OF SOCIAL INTERACTIONS AND PREVENTIVE BEHAVIORS}

This section presents a simple model of social interactions for malaria preventive behaviors based on Glaeser and Scheinkman (2001) and Blume et al. (2011). Although in our empirical study we analyze both sleeping under a bednet and taking an antimalarial drug during pregnancy, in the theoretical model we only focus on sleeping under a bednet to simplify the exposition.

For each time period $t$, assume that the population is arranged in $G$ non-overlapping groups $(g=1, \ldots, G)$. We consider a mother of a child that is identified with an integer $i$ and who belongs to group $g$ at time $t$. The number of children in the group at time $t$ is denoted $n_{g t}$. We assume that the utility enjoyed by the mother depends on her child preventive behaviors $\left(P_{\text {igt }}\right)$, the expected average preventive behaviors of the other 
children in the group at time $t\left(P_{-i g t}\right)$, and a "taste shock" $\left(\Theta_{i g t}\right)$. Moreover, we assume that the mother's utility is quadratic:

$$
U\left(P_{i g t}, P_{-i g t}, \Theta_{i g t}\right)=\Theta_{i g t} P_{i g t}-\frac{1-\gamma}{2} P_{i g t}^{2}-\frac{\gamma}{2}\left(P_{i g t}-P_{-i g t}\right)^{2}
$$

where $0 \leq \gamma<1$ measures the taste for conformity. We also assume that the "taste shock" can be decomposed as:

$$
\Theta_{i g t} \equiv \alpha+X_{i g t} \beta+X_{-i g t} \delta+v_{g t}+\varepsilon_{i g t}
$$

where $X_{i g t}$ denotes the child-mother characteristics, such as the child age, gender, or the mother's education, and $X_{-i g t}$ represents the average characteristics of the other childrenmothers in the group at time $t$.

The mother chooses the continuous level of preventive behavior for the child that maximizes equation (1) subject to the average preventive behaviors of the other children in the group and her "taste shock." The solution to the maximization of the utility function produces the standard linear-in-means model:

$$
P_{i g t}=\alpha+P_{-i g t} \gamma+X_{i g t} \beta+X_{-i g t} \delta+v_{g t}+\varepsilon_{i g t}
$$

where the taste for conformity, $\gamma$, measures endogenous social interactions and $\delta$ gives exogenous (contextual) social interactions. ${ }^{2}$ Endogenous social interactions reflect the influence of the other children's preventive behaviors on child $i$ 's preventive behavior. In our application, endogenous social interactions may arise when mothers are uncertain about the benefits of bednet usage for their children and their expectations of these benefits are a function of the group preventive behavior. Exogenous social interactions arise when the characteristics of the other children and mothers in the group, $X_{-i g t}$, affect child $i$ preventive behaviors through social pressure. For example, a group with a large percentage of highly educated mothers may make sleeping under a bednet the social norm

\footnotetext{
${ }^{2}$ The model described by equations (1) and (2) is convenient to solve, but imposes unrealistic assumptions. In particular, it assumes that $P_{i g t}$ is a continuous variable and that there are no cross products between $P_{-i g t}$ and $X_{-i g t}$. We interpret equation (3) as a linearization of some unknown non-linear function that represents the solution of the true model.
} 
for all children in the group.

We assume that $v_{g t}$ represents the group effect at time $t$ that is observable to all mothers in the group at time $t$, but unobervable to us. We allow $v_{g t}$ to be correlated with $X_{i g t}$ and $X_{-i g t}$. Finally, $\varepsilon_{i g t}$ is the individual idiosyncratic component. We assume that $E\left(\varepsilon_{i g t} \mid X_{i g t}, X_{-i g t}, v_{g t}\right)=0$ and that $\varepsilon_{i g t}$ is uncorrelated with $\varepsilon_{i^{\prime} g^{\prime} t^{\prime}}$ for each $i \neq i^{\prime}$ or $g \neq g^{\prime}$ or $t \neq t^{\prime}$.

Taking the expected value at the group-time level on both sides of equation (3) and solving for $P_{-i g t}$ leads to the social equilibrium for the group:

$$
P_{-i g t}=\frac{\alpha}{1-\gamma}+X_{-i g t}\left(\frac{\beta+\delta}{1-\gamma}\right)+\frac{v_{g t}}{1-\gamma}
$$

Substituting (4) into (3) and replacing $X_{-i g t}$ with its sample counterpart $\bar{X}_{g t}=$ $\frac{1}{m_{g t}} \sum_{i} X_{i g t}$ leads to the following individual-level equation: ${ }^{3}$

$$
P_{i g t}=\frac{\alpha}{1-\gamma}+X_{i g t} \beta+\bar{X}_{g t}\left(\frac{\gamma \beta+\delta}{1-\gamma}\right)+\frac{v_{g t}}{1-\gamma}+\varepsilon_{i g t}^{*}
$$

where

$$
\varepsilon_{i g t}^{*}=\varepsilon_{i g t}+\left(\frac{\gamma \beta+\delta}{1-\gamma}\right)\left(X_{-i g t}-\bar{X}_{g t}\right)
$$

Taking sample group-time averages in (3) and solving for $\bar{P}_{g t}=\frac{1}{m_{g t}} \sum_{i} X_{i g t}$ leads to the group-level equation:

$$
\bar{P}_{g t}=\frac{\alpha}{1-\gamma}+\bar{X}_{g t}\left(\frac{\beta+\delta}{1-\gamma}\right)+\frac{v_{g t}}{1-\gamma}+\bar{\varepsilon}_{g t}^{\prime}
$$

where

$$
\bar{\varepsilon}_{g t}^{\prime}=\frac{\gamma\left(P_{-i g t}-\bar{P}_{g t}\right)+\delta\left(X_{-i g t}-\bar{X}_{g t}\right)+\bar{\varepsilon}_{g t}}{1-\gamma}
$$

Following Glaeser and Scheinkman (2001), Glaeser et al. (2003), Auld (2011), and Canning et al. (2013), the social multiplier is the ratio of the effect of characteristic $X$ on preventive behaviors at the group level over its effect on preventive behaviors at the

\footnotetext{
${ }^{3}$ We only observe a sample $m_{g t}<n_{g t}$ of individuals from each group $g$ at time $t$. This creates a measurement error for variables based on sample averages.
} 
individual level. In other words, the social multiplier is the ratio of $\frac{\beta+\delta}{1-\gamma}$ from equation (6) and $\beta$ from equation (5), that is:

$$
\text { Social Multiplier }=\frac{\frac{\beta+\delta}{1-\gamma}}{\beta}
$$

In the absence of social interactions $(\gamma=0$ and $\delta=0)$, the social multiplier equals 1 because the effect of any characteristic on preventive behaviors is the same at the individual level and at the group level. In contrast, in the presence of endogenous social interactions $(0<\gamma<1)$ and assuming no exogenous social interactions $(\delta=0)$, the

social multiplier equals $\frac{1}{1-\gamma}$ and is thus greater than one. Symmetrically, when there is no endogenous social interaction $(\gamma=0)$ and only exogenous social interactions $(\delta \neq 0)$, and provided that $\beta$ and $\delta$ have the same sign, the social multiplier is also greater than one. Finally, when there are both endogenous and exogenous social interactions $(0<\gamma<1$ and $\delta \neq 0$ ), and provided that $\beta$ and $\delta$ have the same sign, the social multiplier is also greater than one.

\section{IDENTIFICATION AND ESTIMATION STRATEGY}

This section is divided into four subsections. First, we define our reference group and discuss the implications of this choice. Second, we present the contextual effects we focus on in this study. Third, we examine the identification of the individual-level model. Fourth, we discuss the identification of the regional-level model.

\subsection{Reference Group}

We define an individual's reference group as all the individuals who live in the same region, split into its urban and rural parts. This is the most precise level of disaggregation we can use in our data, as the (split) region is the smallest geographical entity that we can follow over time. The construction of the geographical regions is presented in details in Section 4.

Note that all of our survey samples are collected from geographical clusters which are smaller and more precise than regions. However, we do not use the cluster as our 
reference group for two reasons. First, within any country, the clusters selected change in each survey. It is therefore impossible to apply cluster fixed effects in our group-level regressions. Second, the number of children under 5 and pregnant women within each cluster is small, and so measurement error in calculating group averages would be large.

In this paper, we measure the social interactions that occur within (split) regions. However, there might also be social interactions across urban and rural areas within the same region, or across regions, or even across countries. We expect the social multiplier to increase with the level of aggregation. As a consequence, we interpret our results on the social multiplier within (split) regions as lower bounds.

In addition to larger geographical areas (the unsplit region, the country, a set of countries), the reference group could also be defined by cultural traits such as ethnicity, local dialect, or religion. In the future, researchers may be interested in investigating social interactions using these alternative definitions of the group.

\subsection{Explanatory Variables and Exogenous Social Interactions}

Our models of bednet usage include the following list of explanatory variables: the child's age and gender, the mother's age and education, household size, and household wealth. In our analysis of preventive treatment during pregnancy, we control for the woman's age and education, household size, and household wealth.

When we examine the social multipliers, we focus on the mother or woman's education and on household wealth, because these variables can be influenced by governmental policies on the one hand, and because they are likely to generate exogenous social interactions on the other hand. We expect educated and wealthy women to be more likely to use preventive methods (because they understand their benefits) and to be respected and imitated by their neighbors. Consequently, we expect education and wealth to generate exogenous social interactions, meaning that a woman's decision regarding prevention will be positively influenced by the average education and wealth level in her group. 


\subsection{Individual-Level Model}

We use the individual-level model in equation (5) to identify the denominator of the social multiplier, $\beta$. We estimate this equation including cluster fixed effects, which are time variant. The inclusion of these cluster fixed effects perfectly control for unobserved factors that affect malaria preventive behaviors for everyone in the cluster at time $t$ such as malaria campaigns, weather, and earning prospects. Unfortunately in equation (5), the inclusion of cluster fixed effects captures any characteristic that is region-time specific. Consequently, the inclusion of these fixed effects does not allow us to identify the coefficients on $\bar{X}_{g t}$.

\subsection{Aggregate-Level Model}

We use the aggregate-level equation (6) to identify the numerator of the social multiplier, $\frac{\beta+\delta}{1-\gamma}$.

\subsubsection{Main Model}

In our main model, we decompose $v_{g t}$ into three effects: (i) a time-invariant groupspecific effect $v_{g}$, (ii) a vector of country (c) specific time-variant controls $Z_{1 c t}$, and (iii) a vector of region-specific time-variant controls $Z_{2 g t}:{ }^{4}$

$$
\begin{aligned}
\bar{P}_{g t}= & \frac{\alpha}{1-\gamma}+\bar{X}_{g t}\left(\frac{\beta+\delta}{1-\gamma}\right)+\frac{v_{g}}{1-\gamma} \\
& +\frac{\theta_{1} Z_{1 c t}}{1-\gamma}+\frac{\theta_{2} Z_{2 g t}}{1-\gamma}+\bar{\varepsilon}_{g t}^{\prime}
\end{aligned}
$$

$v_{g}$ controls for omitted factors that are time invariant and affect the malaria preventive behaviors for everyone in the group (for instance, the level of malaria prevalence or the ethnic composition of the group). Moreover, $Z_{1 c t}$ controls for time-variant omitted factors that affect the malaria preventive behaviors of everyone in the country. $Z_{1 c t}$ includes a survey (i.e. country-time) dummy and country-specific time trends and their squares. Finally, $Z_{2 g t}$ captures omitted factors that affect high malaria prevalence regions differently,

\footnotetext{
$\bar{X}_{g t}$.

${ }^{4}$ Controlling for region-time fixed effects is not an option because they are perfectly correlated with
} 
and it controls for time-variant weather-related factors that affect the malaria preventive behaviors of everyone in the region depending on whether the interview is conducted during the rainy or malaria seasons. Specifically, $Z_{2 g t}$ includes an interaction between a time-invariant region-specific malaria ecology index and a time trend, an interaction between the malaria ecology index and a time trend square, and the precipitation and temperature deviations. The precipitation (or temperature) deviation equals the difference between the month of the interview precipitation (or temperature) in the region and the annual average precipitation (or temperature) in the region. The precipitation and temperature deviations are used in the analysis of bednet usage only.

Although the empirical model given in equation (7) controls for many potential omitted factors that might be correlated with $\bar{X}_{g t}$, it does not control for all possible region-time variant factors that might cause an omitted variable bias. This could happen in two situations in particular. First, it is possible that between surveys there are migrations into a region within a country from people of different ethnic backgrounds. This is likely to change the region aggregate levels of education, wealth, and malaria preventive behaviors. Second, it is also possible that national authorities target regions with low education and/or wealth for mass net or IPTp campaigns. ${ }^{5}$

In sum, in our main model, we estimate $\beta$ in equation (5) under weaker assumptions than $\frac{\beta+\delta}{1-\gamma}$ in equation (7) because we control for cluster fixed effects in equation (5), but we only control for survey fixed effects, region fixed effects, country-specific time trends, trends that depend on the level of malaria ecology in the region, and precipitation and temperature deviations in equation (7). To assess the importance of controlling for cluster omitted variable biases, we also estimate equation (5) without cluster fixed effects and including the same controls as in equation (7).

\footnotetext{
${ }^{5}$ We conducted research on the policies of many of the countries in our sample and found that net distribution campaigns tend to be national, without targeting a particular region. For example, in Madagascar (with the exception of three districts in the Vakinankaratra province, which is dropped in our sample) campaigns have been offering ITNs free of charge across the whole country, starting in 2004 (Snow et al., 2012), whereas in Benin, treated nets have continuously been distributed nation-wide for pregnant women and children after malaria was declared the most important disease for children under 5 in 2007 (Damien et al., 2010).
} 


\subsubsection{Measurement Error and Split-Sample IV Model}

Another potential source of bias when estimating equation (7) is measurement error in the explanatory and dependent variables, since we use the sample averages instead of the true population averages $\left(\bar{\varepsilon}_{g t}^{\prime}=\left(\gamma\left(P_{-i g t}-\bar{P}_{g t}\right)+\delta\left(X_{-i g t}-\bar{X}_{g t}\right)+\bar{\varepsilon}_{g t}\right) /(1-\gamma)\right.$ in equation (7)).

Measurement error in the explanatory variables is likely to lead to an attenuation bias as in the classical error-in-variables model. Following Graham and Hahn (2005), Canning et al. (2013), and Auld (2011), we correct for measurement error in the explanatory variables using the split-sample IV method proposed by Angrist and Krueger (1995). In this method, we randomly split the sample within each (split) region and year into two subgroups 1 and 2, and we calculate the means of the characteristics for the subgroups, $\bar{X}_{(1) g t}$ and $\bar{X}_{(2) g t}$. Because of the random assignment into the subgroups, measurement errors in $\bar{X}_{(2) g t}$ are uncorrelated with measurement errors in $\bar{X}_{(1) g t}$. We can then use $\bar{X}_{(2) g t}$ as instruments for $\bar{X}_{(1) g t}$ to get consistent estimates of the regional means.

Measurement error in the dependent variable may create a bias if women in regions with high levels of education and wealth missreport/overstate their preventive behaviors due to social pressure. We assume that the potential bias due to correlations between the measurement error in the dependent variable and the explanatory variables is small and can be ignored.

\section{DATA}

The data come from the Demographic and Health Surveys (DHS), Malaria Indicator Surveys (MIS), AIDS Indicator Surveys (AIS), and Multiple Indicator Cluster Surveys (MICS) for countries in Sub-Saharan Africa. These surveys are large and nationally representative. DHS, MIS, and AIS are part of the MEASURE DHS project, which is partially funded by USAID. The goal of the DHS project is to monitor the population and health situations of the target countries. DHS/MIS/AIS data contain detailed information on health and preventive health behaviors for children, women, and men. MICS is funded by UNICEF and it is used to monitor the situation of children and women. 
Starting in 1999-2000, DHS/MIS/AIS and MICS began collecting information on the use of mosquito nets, whether the nets are ITNs, and intermittent preventive treatments for past pregnancies (IPTp). Because malaria eradication was not a health policy priority before the creation of the Roll Back Malaria Partnership, DHS/MIS/AIS and MICS do not include questions related to malaria prevention before 1999-2000. Fortunately, DHS, MIS, and AIS use the same basic malaria questions, making comparisons between and within countries using these surveys straightforward. MICS questionnaires are not identical to DHS/MIS/AIS, but comparable measures of malaria prevention between MICS and DHS/MIS/AIS can still be obtained.

DHS/MIS/AIS/MICS samples are drawn from geographical clusters. These clusters are obtained from the previous census enumeration areas (EAs) and they are nationally representative. Clusters vary in size and population but typically contain around 500 individuals. In rural areas, a cluster is usually a village or group of villages, and in urban areas, it is about a city block.

For each individual, the data contain information on his region of residence, his cluster of residence, and whether his cluster is in a urban or rural setting. Our aggregate geographical group is the region of residence split into rural and urban clusters. Thus, we create two groups per region. One group is made of all urban clusters in the region and the other group is composed of all rural clusters in the region.

For some countries, the boundaries of some regions have changed between surveys conducted in different years. In these instances, we combine regions using maps provided in the public report of each survey. We drop groups with less than 100 observations, because small cells would lead to unreliable group estimates.

We restrict our data to countries for which we have at least two usable DHS/MIS/AIS/ MICS surveys containing comparable information on malaria prevention between 1999 and 2012. Table I describes our data. We use 92 surveys (mainly DHS and MICS) covering 29 countries. Malaria is endemic in all the countries we use in our analysis, according to the Roll Back Malaria website. ${ }^{6}$ The number of surveys per country ranges from two (for

\footnotetext{
${ }^{6}$ See www.rollbackmalaria.org/endemiccountries.html
} 
11 countries) to five (for Malawi, Nigeria, Rwanda, and Senegal).

[Insert Table I here]

We merge the DHS/MIS/AIS/MICS regions with monthly precipitation and temperature data from 1999 to 2012 based on weather station observations and interpolations from the Climatic Research Unit (CRU), available at www.cru.uea.ac.uk.

We also merge the DHS/MIS/AIS/MICS regions with a measure of malaria prevalence $\left(\mathrm{PfPR}_{2-10}\right)$ for 2010 obtained from the Malaria Atlas Project (MAP) databases which are publicly available at www.map.ox.ac.uk. PfPR $\mathrm{Pf}_{2-10}$ captures the percentage of children ages 2 to 10 who have detectable levels of the Plasmodium falciparum parasite in their peripheral blood. $\mathrm{PfPR}_{2-10}$ is constructed from parasite surveys that are periodically carried out in areas known to have malaria. Then, using Bayesian geostatistical algorithms with adjustments for climatic and environmental factors, MAP made projections in time and space to create a continuous display of $\mathrm{PfPR}_{2-10}$, called the Malaria Endemicity map, for all of Africa in 2010. Gething et al. (2011) provide details on the construction of $\mathrm{PfPR}_{2-10}$.

\section{EMPIRICAL SPECIFICATION}

Overview: We estimate equations (5) and (7) separately for children under 5 and for women who gave birth over the two years preceding the interview. When estimating equation (5), we use individual-level variables, whereas for equation (7), we use the averages of the variables in the group. ${ }^{7}$

We do not use sample weights because when the model is correctly specified, ordinary least squares results are consistent (Deaton, 1997; Solon et al., 2013). In addition, weights should be based on the population in each region and survey, but we do not have the true populations for all regions and surveys in our data.

Dependent Variables: For children under 5, we study the following dependent variables: (i) whether the child slept under any type of mosquito net the night before

\footnotetext{
${ }^{7}$ An overview of the variables is given in Appendix A.
} 
the survey, and (ii) whether the child slept under an ITN the night before the survey. Sleeping under an ITN is considered to be the main tool to fight malaria in the RBM partnership arsenal.

For women who gave birth over the two years preceding the interview, we use the following dependent variables: (i) whether the woman took at least one dose of Fansidar during her last pregnancy, and (ii) whether the woman took at least two doses on Fansidar during her last pregnancy. WHO recommendation is that women take two doses of Fansidar. In that case, it is considered that they complete the IPTp treatment.

Explanatory Variables: In the children models, we control for the mother's education, household wealth, child age, whether the child is a male, the mother's age, and household size. In the women analysis, we include controls for the woman's education, household wealth, the woman's age, and household size. The mother or woman's education is a binary indicating whether the mother or woman has secondary education or higher. The wealth variable is a dummy for whether the household has an improved source of drinking water or improved sanitation facilities. ${ }^{8}$

Our specifications also include controls for cluster fixed effects (equation (5)), survey fixed effects (equation (7)), region fixed effects (equation (7)), country-specific trends (equation (7)), trends interacted with malaria ecology (equation (7)), and precipitation and temperature deviations (equation (7), children sample).

The malaria ecology index captures the variation in malaria prevalence in the region that is explained by climatic factors. We construct the malaria ecology index using $\mathrm{PfPR}_{2-10}$ for 2010 , the average precipitation and temperature data, the average maximum precipitation and temperature, and the average minimum precipitation and temperature. The average precipitation (temperature) is the mean precipitation (temperature) between 2000 and 2010. To quantify the average maximum precipitation (temperature), we find the month with the highest average precipitation (temperature) in the region for each year and then average over all the years. Using the same procedure, we find the average

\footnotetext{
${ }^{8}$ The DHS/MIS/AIS contain an index of wealth reported in quintiles. This index is calculated based on questions related to the possession of assets such as a radio or a bicycle. We do not use this measure, because it is not comparable across surveys.
} 
minimum precipitation (temperature). We then take the squares, cubes, and quartics of each of the six climate variables, leaving us with 24 climate variables.

We then regress malaria prevalence $\left(\mathrm{PfPR}_{2-10}\right.$ in 2010) on our 24 climate variables. The fit of the resulting prediction, with an $R^{2}$ of 0.63 , is very high (see Appendix B). Our malaria ecology index is the prediction of malaria prevalence from this regression.

When estimating equation (7) for the children sample, we control for precipitation and temperature deviations. The precipitation (respectively temperature) deviation variable captures the difference between the month of the interview precipitation (temperature) and the annual average precipitation (temperature) in the region. These deviations are calculated as follows. We begin by taking the level of precipitation (temperature) for each region in each month from 1999 to 2012. We then take the average over the 12 months preceding the interview to get the annual average precipitation (temperature) for a region. The deviation is just the month of the interview precipitation (temperature) minus the annual average precipitation (temperature) for each region.

\section{MAIN RESULTS}

\subsection{Descriptive Statistics}

Descriptive statistics are reported in Table II. In column (1), we show the descriptive statistics for the individual-level data, whereas in columns (2) to (4), we present the descriptives for the regional-level data. While column (2) contains the descriptives for the whole period 1999-2012, columns (3) and (4) present them for the sub-periods 1999-2005 and 2006-2012.

Column (1) shows that only $29 \%$ of children under 5 slept under a bednet the night before the survey and only $21 \%$ slept under an ITN. The percentage of women who took at least one dose of Fansidar is $34 \%$, but the percentage who took at least two doses of Fansidar is only $18 \%$. The mean child age is 2 years and the mean mother or women's age is around 27 years. Only $13-15 \%$ of mothers or women have secondary education and the average household size is approximately 8 members. 
Column (2) contains the regional-level statistics for 1999-2012. Note that as expected the means at the regional level in column (2) are different from the means at the individual level in column (1). However, the differences between columns (1) and (2) are generally small, because the regions are rather homogenous, implying that the means of the variables are rather similar across regions. By contrast, for women's preventive behaviors, the means in column (2) are different from those in column (1): this is due to the heterogeneity in preventive treatment between regions (with some regions where preventive treatment is common and others where it is rare), and to the fact that regions have different sample sizes.

When we break up the 1999-2012 period into two sub-periods, 1999-2005 in column (3) and 2006-2012 in column (4), we see that the regional means of all four preventive behaviors increase over time, but the increase is substantially stronger for sleeping under an ITN and taking two doses of Fansidar. Similarly, among the explanatory variables, the share of educated mothers and of wealthy households also improve over time.

The sample size for the individual-level models varies from 88,316 observations for taking two doses of Fansidar to 662,105 observations for sleeping under any type of bednet. For the regional-level regressions, the sample size ranges from 356 to 1,436 observations.

[Insert Table II here]

\subsection{Main Model}

Table III displays the regression results of our main model, for sleeping under any type of bednet in Panel A and for sleeping under an ITN in Panel B. Columns (1) to (3) give the results of the individual-level regressions, whereas column (4) gives the results of the regional-level regression. Column (1) presents the results without controlling for any fixed effect, column (2) controls for the exact same fixed effects as in the regional-level model in column (4), and column (3) controls for cluster fixed effects.

[Insert Table III here]

In both Panels A and B, the coefficients on children's and women's demographics in column (1) are somewhat different from those in models that do control for fixed effects 
in columns (2) and (3). This highlights that adequately controlling for unobserved factors is necessary for our study. As a consequence, we will not comment on the results from column (1).

In Panel A, individual models in columns (2) and (3) show that the mother's secondary education increases the probability that the child sleeps under any type of bednet by 6.7 and 5.6 percentage points. In the regional model in column (4), the coefficient on the mother's secondary education is larger than in individual-level models, since maternal education increases the probability that the child sleeps under any type of bednet by 12.7 percentage points. Moreover, individual-level models in columns (2) to (3) show that household wealth increases the probability that the child sleeps under any type of bednet by 3.2 and 2.2 percentage points. Again, the effect of wealth in the regional-level model is greater, since wealth increases the probability that the child sleeps under any type of bednet by 4.4 percentage points. However, the coefficient on wealth is not significant.

In Panel B, we find that the coefficient on the mother's education is greater in the regional-level model in column (4) than in the individual-level models in columns (2) and (3). However, the coefficients on education and wealth are not significant in the regionallevel model. Our specification includes country-specific time trends that together with (split) region fixed effects explain most of the variation in ITN usage at the group level.

All models indicate that sleeping under any type of bednet or under an ITN does not depend on the child gender, since the coefficient for the child being a male is generally small and is never significant. The effect of household size on bednet and ITN usage is negative in our models, but the coefficient is significant in individual-level models only. This finding is consistent with competition for resources within households: for a given number of bednets and ITNs within a household, the likelihood that a bednet is allocated to a child decreases with the number of household members.

Table IV reports the estimates for the preventive outcomes for women. Panel A contains the results for taking at least one dose of Fansidar, whereas Panel B reports the coefficients for taking two doses of Fansidar, which corresponds to the WHO recommendation for pregnant women. 
In Panel A, specifications in columns (2) to (4) indicate that women with secondary education are significantly more likely to adopt preventive behaviors than women with no education or primary education only. This is an expected result, since women with a higher education are more likely to be aware of the benefits of antimalarial drugs. We also find that the coefficient on education in the regional-level regression in column (4) is much larger than the coefficient in individual-level regressions in columns (2) and (3). Similarly, the coefficient on household wealth is positive, significant, and greater in the regional-level model than in the individual-level models. Results in Panel B are consistent with those in Panel A, but the coefficients on education and wealth in the regional-level models are not significant.

In both Tables III and IV, the estimated parameters in columns (2) and (3) are rather similar, but they are different from the parameters in column (1). This suggests that our decomposition of the unmeasured group effect, $v_{g t}$ (into survey fixed effects, region fixed effects, different time trends, and precipitation and temperature deviations) is sufficient to control for the omitted variable bias.

The social multipliers associated with education and wealth are reported in Table V.

\section{[Insert Table V here]}

The social multipliers for the mother's or woman's secondary education are computed by dividing the coefficients on the mother's or woman's secondary education from the regional-level regression in Tables III and IV, column (4), by the coefficients on the mother's or woman's secondary education from the individual-level regressions, in Tables III and IV, column (3). We use the same procedure to calculate the social multipliers for wealth. We use bootstrap methods to calculate the $95 \%$ confidence intervals of the social multipliers (Li and Maddala, 1999): 1,000 bootstrap samples are taken with randomization at the country and regional level respectively (to maintain the panel structure of the data). Note that the $95 \%$ confidence intervals of the multipliers are not symmetric; symmetry of the confidence interval for a ratio only occurs in very large samples. 
The social multipliers for education and wealth are significantly greater than one for sleeping under any type of bednet, taking one dose of Fansidar or more, and taking two doses of Fansidar or more. This suggests that the decision to adopt preventive behaviors does not only depend on women's education or household wealth, but also on the average women's education and household wealth in the region, and that there are spillovers between households.

In addition, while the multipliers associated with sleeping under any type of bednet are rather modest, those for antimalarial treatments during pregnancy are large. At first sight, these large multipliers may seem implausible. However, the large social multipliers for women's preventive behaviors could also really capture the existence of strong social interactions. In particular, that social interactions matter more for women's treatment uptake than for children's bednet usage makes sense, since getting preventive treatment is a public/social activity, whereas using a bednet is more private. It is easier for a woman to observe her neighbor going to a health facility to get preventive treatment, than to observe her neighbors' child using a bednet at night. As a consequence, knowledge about the neighbors' preventive treatment uptake is more widespread, which should increase the level of social interactions.

For sleeping under an ITN, we do not find that the social multipliers of education and wealth are significantly greater than one. It is not clear whether this result reflects an absence of social interactions for ITN usage or a lack of statistical power in the regionallevel model due to the lack of variation in our variables once we control for region fixed effects and several time trends.

\subsection{Split-Sample IV Model}

Tables VI reports the results of the split-sample IV method that corrects for measurement error in education and wealth in the regional-level model (see Section 3.4.2).

Column (1) contains the estimates from the regional-level model estimated with OLS (from Tables III and IV), whereas column (2) reports the estimates when using SSIV. For all four dependent variables, the first-stage F-statistics and Kleibergen-Paap Wald Fstatistics are large and we can reject the null hypothesis that the model is not identified. 
The coefficients from the SSIV model are rather similar to the ones from the OLS model, which suggests that measurement error is small in our study and can be ignored.

[Insert Table VI here]

\section{ROBUSTNESS CHECKS AND ADDITIONAL RESULTS}

\subsection{GMM/IV Model}

We here relax the assumption that survey fixed effects, region fixed effects, countryspecific time trends, malaria ecology interacted with time trends, and precipitation and temperature deviations completely address the endogeneity of $\bar{X}_{g t}$ in equation (7). Our strategy is to take the first difference in equation (7) and then use lagged values of $\bar{X}_{g t}$ as instruments, in a GMM/IV framework. Unfortunately, these intruments are weak and most of the coefficients are unreliable. The method and results are presented in Appendix C.

\subsection{Controlling for Wealth Inequality}

We re-estimate our models controlling for wealth inequality. We proxy wealth inequality with the standard deviation of wealth within the region for the year of the interview. The results are reported in the online Appendix D, Table D.I. Note that we control for wealth inequality in regional-level models, but not in individual-level models, because in individual-level models, cluster fixed effects already capture the impact of any variable that is fixed for any region-year.

In Table D.I, the individual-level estimates are thus the same as in Tables III and IV. In Panels A, C and D, the regional-level coefficients on education and wealth are generally comparable to those in Tables III and IV and they are greater than individuallevel coefficients (note that in the regional-level model, the coefficient on household wealth for one dose of Fansidar or more is no longer significant though). Consequently, the social 
multipliers on education and wealth will remain greater than one for sleeping under any type of bednet and taking one or two doses of Fansidar or more. ${ }^{9}$

\subsection{East and West Africa}

We also consider differences in social interactions between East and West Africa. We cannot detect any heterogeneity because of a lack of statistical power. The results of this analysis are reported in the online Appendix E.

\subsection{Excess Variance Across Groups}

We finally check the robustness of our findings on the presence of social interactions in malaria preventive behaviors by analyzing whether there is excess variance of preventive behaviors across groups. Glaeser, Sacerdote, and Scheinkman (1996) and Graham (2008) show that we can measure social interactions based on covariance restrictions of the disturbances. In particular, social interactions create excess variance across groups and these variances depend on the group size. Graham (2008) show that under the assumption of random assignment for the linear-in-means model, we can identify social interactions by using differences in the variance of outcomes of groups of different sizes. Unfortunately, we do not have information on the group sizes (e.g. the population of the split regions) and we cannot implement this method.

Our approach follows Auld (2011) and is based on comparing the actual estimated standard deviation of our outcome across groups:

$$
S_{P_{\text {group }}}=\sqrt{\frac{1}{\# \text { group }} \sum_{g t=1}^{\# \text { group }}\left(\bar{P}_{g t}-\bar{P}\right)^{2}}
$$

where $\bar{P}=\frac{1}{N} \sum_{i=1}^{N} P_{i g t}$ and $\bar{P}_{g t}=\frac{1}{N_{g t}} \sum_{i=1}^{N_{g t}} P_{i g t}$; with the estimated standard deviation assuming that $P_{i g t}$ is i.i.d. with the same mean and standard deviation as in the actual data. If social interactions are present under the assumption of random assignment and

\footnotetext{
${ }^{9}$ Note that other factors, such as the perception of the value of life, may have an impact on the decision to adopt preventive behaviors against malaria. Our data do not contain information on such perceptions though. If we assume that the perception of the value of life is the same for all individuals in any cluster, then our individual-level models with cluster fixed effects already control for the perception of the value of life. However, this might be a strong assumption. We leave this point for future research.
} 
no unmeasured group effects, the group standard deviation using actual data will be larger than the group standard deviation using counterfactual data.

We consider two different group definitions: 1) cluster-time combinations of individuals, and 2) region-time combinations of individuals.

Because many differences in the group variances are caused by individual and group characteristics, we repeat the analysis but in a first stage we regress $P_{\text {igt }}$ on individual characteristics, time trends and region fixed effects, and we then use the residuals to calculate the standard deviations.

In Appendix F, Table F.I, Panel A shows the results for the standard deviations based on the raw data. We find that there is an excess variance at the group level that becomes larger with the size of the group. In Panel B, we control for individual characteristics, time trends, and region fixed effects, and still find excess variance at the group level. We need to be cautious when interpreting these results because this method does not control for unmeasured heterogeneity across groups. However, the results are consistent with the existence of social interactions.

\section{CONCLUSION}

If the Millennium Development Goal of the United Nations of eliminating all avoidable deaths caused by malaria is to be achieved, the level of malaria prevention must not only increase substantially from current levels, but must also remain high and become the new social norm. This paper examines whether there is a social multiplier in the adoption of mosquito nets by children and preventive treatment during pregnancy by women. This social multiplier can be caused by either endogenous social interactions, exogenous social interactions, or both. In this paper, although we cannot examine the source of social interactions, we can identify their existence by quantifying the social multiplier. As far as we are aware, we are the first to investigate this topic.

Our results are consistent with the possibility of large social multipliers associated with education and wealth for antimalarial drugs take up during pregnancy and more modest social multipliers for bednet usage. These results are plausible. In Africa, antimalarial 
drugs during pregnancy are administered during visits to antenatal clinics. Everyone in a particular neighborhood can observe if a woman is pregnant and whether she attends the antenatal clinic as scheduled. In contrast, sleeping under a bednet is not easily observable for individuals outside the household. Thus, peer pressure and the opportunities for social interactions are likely to be larger for antimalarial drugs during pregnancy compared to bednet usage.

The existence of social multipliers suggests that the steady state or long-run effect of a policy that increases the use of bednets or antimalarial treatments during pregnancy (promotional campaigns or subsidies of bednets and treatments) will be larger than what we would have predicted using the individual-level coefficients, once all the indirect effects caused by social interactions are accounted for. Moreover, when combined with investments in education and infrastructure, these policies will generate large multiplier effects. Thus, the cost of achieving the Millennium Goals will be smaller than in the absence of spillovers. 


\section{ACKNOWLEDGEMENTS}

The authors thank the editor Owen O'Donnell, two anonymous referees, Christopher Auld, Kofi Awusabo-Asare, Anirban Basu, Luc Behaghel, Massimiliano Bratti, Pascaline Dupas, Stacey Gelsheimer, Pierre-Yves Geoffard, Laurent Gobillon, Andrew Jones, Lahiri Kajal, Robyn Kibler, Jose Carlos A. Kimou, Sebastian Linnemayr, Carine Milcent, Drah Hannah Owusua, Thomas Piketty, Grégory Ponthière, Bastian Ravesteijn, Silvana Robone, Pedro Rosa Dias, Nicole Schoenecker, Tom Van Ourti, Atheendar Venkataramani, Bruno Ventelou, Joshua Wilde, Arseniy Yashkin, participants at the conferences "Economics of Disease" (2013) and Journées Louis-André Gérard-Varet (2013), a seminar in Paris School of Economics (2013), the Congress of the European Economic Association (2013), the Twenty Second European Workshop on Econometrics and Health Economics (2013), and especially Michael Darden, for useful comments. Research assistance of Stacey Gelsheimer, Robyn Kibler, and Arseniy Yashkin was greatly appreciated. This paper was partially written while Bénédicte Apouey was an Assistant Professor in Economics at the University of South Florida. The authors thank the support of Grant Number R03TW009108 from Fogarty International Center. The content is solely responsibility of the authors and does not necessarily represent the official views of the Fogarty International Center or the National Institute of Health. 


\section{REFERENCES}

Angrist J, Krueger A, 1995. Split-sample instrumental variable estimates of the return to schooling. Journal of Business and Economic Statistics 13: 225-235.

Auld MC, 2011. Effect of large-scale social interactions on body weight. Journal of Health Economics 30: 303-316.

Bernheim BD, 1994. A theory of conformity. Journal of Political Economy 102: 841877.

Binka FN, Kubaje A, Adjuik M, Williams LA, Lengeler C, Maude GH, Armah GE, Kajihara B, Adiamah JH, Smith PG, 1996. Impact of permethrin impregnated bednets on child mortality in Kassena-Nankana district, Ghana: a randomized controlled trial. Tropical Medicine and International Health 1: 147-154.

Blume LE, Brock WA, Durlauf SN, Jayaraman R, 2011. Linear Social Network Models. Unpublished manuscript. Available at http://www.econ.cam.ac.uk/conf/networks-docs/bbdj08-19-11.pdf

Canning D, Günther I, Linnemayr S, Bloom D, 2013. Fertility choice, mortality expectations and interdependent preferences. European Economic Review 63: 273-289.

Cohen J, Dupas P, 2010. Free distribution or cost-sharing? Evidence from a randomized malaria prevention experiment. Quarterly Journal of Economics CXXV: 1-45.

Conley T, Udry C, 2010. Learning about a new technology: pineapple in Ghana. American Economic Review 100: 35-69.

Damien GB, Djènontin A, Rogier C, Corbel V, Bangana SB, Chandre F, Akogbéto M, Kindé-Gazard D, Massougbodji A, Henry M-C, 2010. Malaria infection and disease in an area with pyrethroid-resistant vectors in southern Benin. Malaria Journal 9: 380 .

Deaton A, 1997. The Analysis of Household Surveys. Baltimore: Johns Hopkins University Press.

Dupas P, 2009. What matters (and what does not) in households' decision to invest in malaria prevention? American Economic Review 99: 224-230.

Ellison G, Fudenberg D, 1993. Rules of thumb for social learning. Journal of Political Economy 101: 612-643.

Gething PW, Patil AP, Smith DL, Guerra CA, Elyazar IR, Johnston GL, Tatem AJ, Hay SI, 2011. A new world malaria map: Plasmodium falciparum endemicity in 2010. Malaria Journal 10: 1475-2875.

Glaeser E, Sacerdote B, Scheinkman JA, 1996. Crime and social interactions. Quarterly Journal of Economics CXI: 507-548. 
Glaeser EL, Sacerdote BI, Scheinkman JA, 2003. The social multiplier. Journal of the European Economic Association 1: 345-353.

Glaeser E, Scheinkman JA. Non-market interactions. Advances in economics and econometrics: theory and applications. Eighth World Congress of the Econometric Society. 2002.

Goodman CA, Mills AJ, 1999. The evidence base on the cost-effectiveness of malaria control, measures in Africa. Health Policy and Planning 14: 301-312.

Graham BS, 2008. Identifying social interactions through conditional variance restrictions. Econometrica 76: 643-660.

Graham BS, Hahn J, 2005. Identification and estimation of the linear-in-means model of social interactions. Economics Letters 88: 1-6.

Lengeler C, 2004. Insecticide-treated bed nets and curtains for preventing malaria. Cochrane Database of Systematic Reviews 2.

Li H, Maddala GS, 1999. Bootstrap variance estimation of nonlinear functions of parameters: an application to long-run elasticities of energy demand. Review of Economics and Statistics 81: 728-733.

Malaria Atlas Project (MAP). Available from www.map.ox.ac.uk.

Manski CF, 1993. Identification of endogenous social effects: the reflection problem. Review of Economic Studies 60: 531-542.

Picone G, Kibler R, Apouey B, 2013. Malaria prevalence, indoor residual spraying, and insecticide-treated net usage in Sub-Saharan Africa. Working paper series, Paris School of Economics, No. 2013-40.

Solon G, Hayder, Wooldridge J, 2013. What are we weighting for? Working paper, Michigan State University.

Roll Back Malaria (RBM) Partnership 2010. World Malaria Day 2010: Africa Update. RBM Progress and Impact Series. No 2.

Snow RW, Amratia P, Kabaria CW, Noor AM, Marsh K, 2012. The changing limits and incidence of malaria in Africa: 1939-2009. Advances in Parasitology 78: 169-262.

Wiseman V, Hawley WA, Ter Kuile FO, Phillips-Howard PA, Vulule JM, Nahlen BL, Mills AJ, 2003. The cost-effectiveness of permethrin-treated bednets in an area of intense malaria transmission in western Kenya. American Journal of Tropical Medicine and Hygiene 68: 61-67.

World Health Organization (WHO) 2012 - World Malaria Report. Available at http://www.who.int/malaria/publications/world_malaria_report_2012/en/index.html 
Table I. Data sources

\begin{tabular}{|c|c|c|c|}
\hline Country & $\begin{array}{c}\text { No. } \\
\text { waves }\end{array}$ & $\begin{array}{l}\text { No. } \\
\text { regions }\end{array}$ & Surveys \\
\hline Angola & 3 & 17 & MICS01, MIS06, MIS11 \\
\hline Benin & 2 & 6 & DHS01, DHS06 \\
\hline Burkina Faso & 3 & 13 & DHS03, MICS06, DHS10 \\
\hline Burundi & 4 & 17 & MICS00, MICS05, DHS10, DHS12 \\
\hline Cameroon & 4 & 12 & MICS00, DHS04, MICS06, DHS11 \\
\hline Central African Republic & 2 & 17 & MICS00, MICS06 \\
\hline Chad & 2 & 8 & MICS01, DHS04 \\
\hline Côte d'Ivoire & 4 & 11 & MICS00, AIS05, MICS06, DHS11 \\
\hline Democratic Republic of the Congo & 3 & 11 & MICS01, DHS07, MICS10 \\
\hline Gambia & 2 & 8 & MICS00, MICS05 \\
\hline Ghana & 3 & 10 & DHS03, MICS06, DHS08 \\
\hline Kenya & 2 & 8 & DHS03, DHS08 \\
\hline Liberia & 2 & 15 & MIS08, MIS11 \\
\hline Madagascar & 4 & 6 & MICS00, DHS03, DHS08, MIS11 \\
\hline Malawi & 5 & 26 & DHS00, DHS04, MICS06, DHS10, MIS12 \\
\hline Mali & 2 & 9 & DHS01, DHS06 \\
\hline Mozambique & 2 & 10 & DHS03, DHS11 \\
\hline Namibia & 2 & 12 & DHS00, DHS06 \\
\hline Niger & 2 & 8 & MICS00, DHS06 \\
\hline Nigeria & 5 & 36 & DHS03, MICS07, DHS08, MIS10, MICS11 \\
\hline Rwanda & 5 & 12 & DHS00, MICS00, DHS05, DHS(I)07, DHS10 \\
\hline Senegal & 5 & 10 & MICS00, DHS05, MIS06, MIS08, DHS10 \\
\hline Sierra Leone & 4 & 4 & MIC00, MICS05, DHS08, MICS10 \\
\hline Swaziland & 3 & 4 & MICS99, DHS06, MICS10 \\
\hline Tanzania & 4 & 21 & DHS04, AIS07, DHS09, AIS11 \\
\hline Togo & 3 & 6 & MICS00, MICS06, MICS10 \\
\hline Uganda & 4 & 4 & DHS00, DHS06, MIS09, DHS11 \\
\hline Zambia & 3 & 9 & MICS00, DHS01, DHS07 \\
\hline Zimbabwe & 3 & 10 & DHS99, DHS05, DHS10 \\
\hline Total & 92 surveys & $340^{*}$ & \\
\hline
\end{tabular}

Notes. AIS stands for AIDS Indicator Survey, DHS for standard Demographic and Health Survey, DHS(I) for interim DHS, MICS for Multiple Indicator Cluster Survey, and MIS for Malaria Indicator Survey.

*Each region will be divided in two (one rural, one urban) in the rest of the analysis and the regions with less than 100 observations will be dropped. 
Table II. Summary statistics

\begin{tabular}{|c|c|c|c|c|}
\hline & \multirow{2}{*}{$\begin{array}{c}\text { Individual level } \\
\text { 1999-2012 } \\
\text { Mean } \\
\text { (Std) }\end{array}$} & \multirow{2}{*}{$\begin{array}{c}\text { Regional level } \\
\text { 1999-2012 } \\
\text { Mean } \\
\text { (Std) }\end{array}$} & \multicolumn{2}{|c|}{ Regional level } \\
\hline & & & $\begin{array}{c}\text { 1999-2005 } \\
\text { Mean } \\
\text { (Std) }\end{array}$ & $\begin{array}{c}\text { 2006-2012 } \\
\text { Mean } \\
\text { (Std) }\end{array}$ \\
\hline Children's preventive outcomes & & & & \\
\hline Sleeping under any type of bednet & $\begin{array}{c}0.296 \\
(0.456)\end{array}$ & $\begin{array}{c}0.289 \\
(0.229)\end{array}$ & $\begin{array}{c}0.192 \\
(0.196)\end{array}$ & $\begin{array}{c}0.349 \\
(0.228)\end{array}$ \\
\hline Sleeping under an ITN & $\begin{array}{c}0.215 \\
(0.411)\end{array}$ & $\begin{array}{c}0.209 \\
(0.221)\end{array}$ & $\begin{array}{c}0.051 \\
(0.074)\end{array}$ & $\begin{array}{c}0.299 \\
(0.226)\end{array}$ \\
\hline Women's preventive outcomes & & & & \\
\hline One dose of Fansidar or more & $\begin{array}{c}0.349 \\
(0.476)\end{array}$ & $\begin{array}{c}0.379 \\
(0.329)\end{array}$ & $\begin{array}{c}0.227 \\
(0.290)\end{array}$ & $\begin{array}{c}0.471 \\
(0.312)\end{array}$ \\
\hline Two doses of Fansidar or more & $\begin{array}{c}0.187 \\
(0.390)\end{array}$ & $\begin{array}{c}0.199 \\
(0.215)\end{array}$ & $\begin{array}{c}0.071 \\
(0.132)\end{array}$ & $\begin{array}{c}0.290 \\
(0.216)\end{array}$ \\
\hline Children's demographics & & & & \\
\hline Mother's secondary education & $\begin{array}{c}0.151 \\
(0.358)\end{array}$ & $\begin{array}{c}0.179 \\
(0.179)\end{array}$ & $\begin{array}{c}0.142 \\
(0.165)\end{array}$ & $\begin{array}{c}0.202 \\
(0.207)\end{array}$ \\
\hline Household wealth & $\begin{array}{c}0.658 \\
(0.474)\end{array}$ & $\begin{array}{c}0.687 \\
(0.240)\end{array}$ & $\begin{array}{c}0.633 \\
(0.246)\end{array}$ & $\begin{array}{c}0.720 \\
(0.230)\end{array}$ \\
\hline Child age & $\begin{array}{c}1.954 \\
(1.419)\end{array}$ & $\begin{array}{c}1.954 \\
(0.108)\end{array}$ & $\begin{array}{l}1.930 \\
(0.103)\end{array}$ & $\begin{array}{c}1.968 \\
(0.109)\end{array}$ \\
\hline Child is male & $\begin{array}{c}0.502 \\
(0.499)\end{array}$ & $\begin{array}{c}0.502 \\
(0.030)\end{array}$ & $\begin{array}{c}0.500 \\
(0.031)\end{array}$ & $\begin{array}{c}0.503 \\
(0.030)\end{array}$ \\
\hline Mother's age & $\begin{array}{c}26.996 \\
(10.753)\end{array}$ & $\begin{array}{l}27.055 \\
(2.674)\end{array}$ & $\begin{array}{l}27.676 \\
(2.199)\end{array}$ & $\begin{array}{l}26.668 \\
(2.866)\end{array}$ \\
\hline Household size & $\begin{array}{l}7.740 \\
(4.821)\end{array}$ & $\begin{array}{l}7.549 \\
(2.369)\end{array}$ & $\begin{array}{l}7.736 \\
(2.269)\end{array}$ & $\begin{array}{c}7.432 \\
(2.424)\end{array}$ \\
\hline Women's demographics & & & & \\
\hline Secondary education & $\begin{array}{c}0.134 \\
(0.341)\end{array}$ & $\begin{array}{c}0.154 \\
(0.190)\end{array}$ & $\begin{array}{c}0.154 \\
(0.192)\end{array}$ & $\begin{array}{c}0.158 \\
(0.188)\end{array}$ \\
\hline Household wealth & $\begin{array}{c}0.639 \\
(0.480)\end{array}$ & $\begin{array}{c}0.658 \\
(0.242)\end{array}$ & $\begin{array}{c}0.616 \\
(0.238)\end{array}$ & $\begin{array}{c}0.703 \\
(0.237)\end{array}$ \\
\hline Age & $\begin{array}{l}27.551 \\
(6.852)\end{array}$ & $\begin{array}{l}27.588 \\
(1.238)\end{array}$ & $\begin{array}{l}27.457 \\
(1.373)\end{array}$ & $\begin{array}{l}28.109 \\
(1.050)\end{array}$ \\
\hline Household size & $\begin{array}{l}7.814 \\
(5.296)\end{array}$ & $\begin{array}{l}7.746 \\
(3.029)\end{array}$ & $\begin{array}{l}7.324 \\
(2.612)\end{array}$ & $\begin{array}{c}7.872 \\
(3.129)\end{array}$ \\
\hline Obs. for Sleeping under any type of bednet & 662,105 & 1,436 & - & - \\
\hline Obs. for Sleeping under an ITN & 601,031 & 1,342 & - & - \\
\hline Obs. for One dose of Fansidar or more & 95,555 & 388 & - & - \\
\hline Obs. for Two doses of Fansidar or more & 88,316 & 356 & - & - \\
\hline
\end{tabular}


Table III. Regressions for preventive behaviors for children (OLS)

\begin{tabular}{|c|c|c|c|c|}
\hline & $\begin{array}{c}\text { Individual } \\
\text { Equation (5) } \\
\text { OLS } \\
(1)\end{array}$ & $\begin{array}{c}\text { Individual } \\
\text { Equation (5) } \\
\text { OLS } \\
(2)\end{array}$ & $\begin{array}{c}\text { Individual } \\
\text { Equation (5) } \\
\text { OLS } \\
(3)\end{array}$ & $\begin{array}{c}\text { Regional } \\
\text { Equation (7) } \\
\text { OLS } \\
(4)\end{array}$ \\
\hline \multicolumn{5}{|c|}{ Panel A. Dependent variable: Sleeping under any type of bednet } \\
\hline Mother's secondary education & $\begin{array}{c}0.0265^{* *} \\
(0.0131)\end{array}$ & $\begin{array}{c}0.0676^{* * *} * \\
(0.0016)\end{array}$ & $\begin{array}{c}0.0563^{* * *} * \\
(0.0042)\end{array}$ & $\begin{array}{c}0.127^{* *} \\
(0.0609)\end{array}$ \\
\hline Household wealth & $\begin{array}{c}0.0403^{* * *} * \\
(0.0117)\end{array}$ & $\begin{array}{c}0.0328^{* * *} * \\
(0.0012)\end{array}$ & $\begin{array}{c}0.0226^{* * *} \\
(0.0021)\end{array}$ & $\begin{array}{c}0.0446 \\
(0.0334)\end{array}$ \\
\hline Age $(/ 10)$ & $\begin{array}{c}-0.138^{* * *} \\
(0.0070)\end{array}$ & $\begin{array}{c}-0.153^{* * *} \\
(0.0036)\end{array}$ & $\begin{array}{c}-0.154^{* * *} \\
(0.0055)\end{array}$ & $\begin{array}{l}0.0828 \\
(0.414)\end{array}$ \\
\hline Male & $\begin{array}{l}-0.0005 \\
(0.0010)\end{array}$ & $\begin{array}{l}-0.0015 \\
(0.0009)\end{array}$ & $\begin{array}{l}-0.0013 \\
(0.0009)\end{array}$ & $\begin{array}{c}-0.0274 \\
(0.115)\end{array}$ \\
\hline Mother's age $(/ 10)$ & $\begin{array}{c}-0.0066^{* * *} \\
(0.0021)\end{array}$ & $\begin{array}{c}0.0026^{* * * *} \\
(0.0007)\end{array}$ & $\begin{array}{c}0.0036^{* * *} * \\
(0.0009)\end{array}$ & $\begin{array}{l}-0.0034 \\
(0.0565)\end{array}$ \\
\hline Household size & $\begin{array}{c}-0.0040^{* * *} \\
(0.0011)\end{array}$ & $\begin{array}{c}-0.0057^{* * *} \\
(0.0001)\end{array}$ & $\begin{array}{c}-0.0062^{* * *} \\
(0.0003)\end{array}$ & $\begin{array}{c}-0.0012 \\
(0.0039)\end{array}$ \\
\hline Malaria ecology * Time trend & & $\begin{array}{c}0.0642^{* * *} \\
(0.0084)\end{array}$ & & $\begin{array}{l}0.0789 * \\
(0.0467)\end{array}$ \\
\hline Malaria ecology $*$ Time trend ${ }^{2}$ & & $\begin{array}{c}-0.0037^{* * *} * \\
(0.0005)\end{array}$ & & $\begin{array}{c}-0.0053^{*} \\
(0.0030)\end{array}$ \\
\hline Precipitation (deviation) $(/ 100)$ & & $\begin{array}{c}-0.0048^{* * *} \\
(0.0008)\end{array}$ & & $\begin{array}{c}0.0024 \\
(0.0054)\end{array}$ \\
\hline Temperature (deviation) & & $\begin{array}{c}-0.0068^{* * *} \\
(0.0003)\end{array}$ & & $\begin{array}{c}-0.0061^{* * *} \\
(0.0021)\end{array}$ \\
\hline Observations & 662,105 & 662,105 & 662,105 & 1,436 \\
\hline R-squared & 0.009 & 0.222 & 0.385 & 0.754 \\
\hline Number of (split) regions & & & & 472 \\
\hline Panel B. Dependent variable: & Sleeping un & er an ITN & & \\
\hline Mother's secondary education & $\begin{array}{l}0.0189^{*} \\
(0.0101)\end{array}$ & $\begin{array}{c}0.0533^{* * *} * \\
(0.0039)\end{array}$ & $\begin{array}{c}0.0451^{* * *} \\
(0.00356)\end{array}$ & $\begin{array}{c}0.0810 \\
(0.0572)\end{array}$ \\
\hline Household wealth & $\begin{array}{c}0.0391 * * * \\
(0.0113)\end{array}$ & $\begin{array}{c}0.0277^{* * * *} \\
(0.0023)\end{array}$ & $\begin{array}{c}0.0179 * * * \\
(0.0021)\end{array}$ & $\begin{array}{c}0.0095 \\
(0.0327)\end{array}$ \\
\hline Age $(/ 10)$ & $\begin{array}{c}-0.106^{* * *} \\
(0.0071)\end{array}$ & $\begin{array}{c}-0.120^{* * *} \\
(0.0053)\end{array}$ & $\begin{array}{c}-0.122^{* * *} \\
(0.0053)\end{array}$ & $\begin{array}{c}0.144 \\
(0.417)\end{array}$ \\
\hline Male & $\begin{array}{c}0.0006 \\
(0.0010)\end{array}$ & $\begin{array}{c}-0.0003 \\
(0.0008)\end{array}$ & $\begin{array}{l}-0.0003 \\
(0.0008)\end{array}$ & $\begin{array}{l}0.0345 \\
(0.113)\end{array}$ \\
\hline Mother's age $(/ 10)$ & $\begin{array}{l}-0.0021 \\
(0.0020)\end{array}$ & $\begin{array}{c}0.0026^{* * *} \\
(0.0009)\end{array}$ & $\begin{array}{c}0.0033^{* * *} \\
(0.0009)\end{array}$ & $\begin{array}{l}-0.0255 \\
(0.0543)\end{array}$ \\
\hline Household size & $\begin{array}{c}-0.0041^{* * *} \\
(0.0010)\end{array}$ & $\begin{array}{c}-0.0044^{* * *} \\
(0.0003)\end{array}$ & $\begin{array}{c}-0.0047^{* * *} * \\
(0.0003)\end{array}$ & $\begin{array}{c}-0.0048 \\
(0.0041)\end{array}$ \\
\hline Malaria ecology $*$ Time trend & & $\begin{array}{c}0.0454 \\
(0.0348)\end{array}$ & & $\begin{array}{l}0.0750^{*} \\
(0.0401)\end{array}$ \\
\hline Malaria ecology $*$ Time trend ${ }^{2}$ & & $\begin{array}{l}-0.0019 \\
(0.0025)\end{array}$ & & $\begin{array}{l}-0.0046 \\
(0.0029)\end{array}$ \\
\hline Precipitation (deviation) (/100) & & $\begin{array}{c}-0.0077^{* *} \\
(0.0030)\end{array}$ & & $\begin{array}{c}-0.0124^{* *} \\
(0.0054)\end{array}$ \\
\hline Temperature (deviation) & & $\begin{array}{l}-0.0010 \\
(0.0017)\end{array}$ & & $\begin{array}{l}-0.0030 \\
(0.0024)\end{array}$ \\
\hline Observations & 601,031 & 601,031 & 601,031 & 1,342 \\
\hline R-squared & 0.007 & 0.260 & 0.396 & 0.815 \\
\hline Number of (split) regions & & & & 430 \\
\hline Average Xs & & Yes & & \\
\hline Region FE & & Yes & & Yes \\
\hline Time trend & & Yes & & Yes \\
\hline Time trend ${ }^{2}$ & & Yes & & Yes \\
\hline Country FE $\times$ Time trend & & Yes & & Yes \\
\hline Country FE $\times$ Time trend ${ }^{2}$ & & Yes & & Yes \\
\hline Survey type FE & & Yes & & Yes \\
\hline Cluster FE & & & Yes & \\
\hline
\end{tabular}

Notes. The precipitation and temperature variables are the deviations from the monthy precipitation and temperature averages.

"Average Xs" include average child age, the proportion of male children, average mother's secondary education, mother's age, household size, and wealth in the region.

Robust standard errors, which are clustered by (split) region, are reported in parentheses.

*** denotes significance at $1 \%$ level. $* *$ denotes significance at $5 \%$ level. $*$ denotes significance at $10 \%$ level. 
Table IV. Regressions for preventive behaviors for women, for child deliveries in the last two years (OLS)

\begin{tabular}{|c|c|c|c|c|}
\hline & $\begin{array}{c}\text { Individual } \\
\text { Equation (5) } \\
\text { OLS } \\
(1) \\
\end{array}$ & $\begin{array}{c}\text { Individual } \\
\text { Equation (5) } \\
\text { OLS } \\
(2) \\
\end{array}$ & $\begin{array}{c}\text { Individual } \\
\text { Equation (5) } \\
\text { OLS } \\
(3) \\
\end{array}$ & $\begin{array}{c}\text { Regional } \\
\text { Equation (7) } \\
\text { OLS } \\
(4) \\
\end{array}$ \\
\hline \multicolumn{5}{|c|}{ Panel A. Dependent variable: One dose of Fansidar or more } \\
\hline Secondary education & $\begin{array}{l}-0.0156 \\
(0.0263)\end{array}$ & $\begin{array}{c}0.0599 * * * \\
(0.0066)\end{array}$ & $\begin{array}{c}0.0507 * * * \\
(0.0067)\end{array}$ & $\begin{array}{c}0.469^{* *} \\
(0.215)\end{array}$ \\
\hline Household wealth & $\begin{array}{c}0.0727^{* * *} \\
(0.0182)\end{array}$ & $\begin{array}{c}0.0306^{* * *} \\
(0.0043)\end{array}$ & $\begin{array}{c}0.0143^{* * *} \\
(0.0047)\end{array}$ & $\begin{array}{c}0.124^{*} \\
(0.0678)\end{array}$ \\
\hline Age $(/ 10)$ & $\begin{array}{c}-0.0168^{* * *} \\
(0.00524)\end{array}$ & $\begin{array}{l}0.0022 \\
(0.0017)\end{array}$ & $\begin{array}{c}0.0021 \\
(0.0019)\end{array}$ & $\begin{array}{l}-0.106 \\
(0.103)\end{array}$ \\
\hline Household size & $\begin{array}{c}0.0097^{* * * *} \\
(0.0020)\end{array}$ & $\begin{array}{l}0.0003 \\
(0.0005)\end{array}$ & $\begin{array}{c}0.0001 \\
(0.0003)\end{array}$ & $\begin{array}{c}0.0086 \\
(0.0101)\end{array}$ \\
\hline Malaria ecology $*$ Time trend & & $\begin{array}{l}-0.0213 \\
(0.0696)\end{array}$ & & $\begin{array}{l}0.0756 \\
(0.0784)\end{array}$ \\
\hline Malaria ecology $*$ Time trend ${ }^{2}$ & & $\begin{array}{c}0.0021 \\
(0.0045)\end{array}$ & & $\begin{array}{l}-0.0042 \\
(0.0051)\end{array}$ \\
\hline $\begin{array}{l}\text { Observations } \\
\text { R-squared } \\
\text { Number of (split) regions }\end{array}$ & $\begin{array}{l}95,555 \\
0.017\end{array}$ & $\begin{array}{l}95,555 \\
0.454\end{array}$ & $\begin{array}{c}95,555 \\
0.580\end{array}$ & $\begin{array}{c}388 \\
0.901 \\
146\end{array}$ \\
\hline \multicolumn{5}{|c|}{ Panel B. Dependent variable: Two doses of Fansidar or more } \\
\hline Secondary education & $\begin{array}{l}-0.0024 \\
(0.0163)\end{array}$ & $\begin{array}{c}0.0379 * * * \\
(0.0053)\end{array}$ & $\begin{array}{c}0.0334^{* * *} \\
(0.0057)\end{array}$ & $\begin{array}{c}0.206 \\
(0.206)\end{array}$ \\
\hline Household wealth & $\begin{array}{c}0.0441 * * * \\
(0.0121)\end{array}$ & $\begin{array}{c}0.0192^{* * * *} \\
(0.0041)\end{array}$ & $\begin{array}{l}0.0081^{*} \\
(0.0048)\end{array}$ & $\begin{array}{c}0.0851 \\
(0.0547)\end{array}$ \\
\hline Age (/10) & $\begin{array}{c}-0.0127^{* * *} \\
(0.0033)\end{array}$ & $\begin{array}{c}0.0005 \\
(0.0015)\end{array}$ & $\begin{array}{l}0.0006 \\
(0.0016)\end{array}$ & $\begin{array}{l}-0.128^{*} \\
(0.0757)\end{array}$ \\
\hline Household size & $\begin{array}{c}0.0084^{* * *} \\
(0.0013)\end{array}$ & $\begin{array}{c}-3.18 \mathrm{e}-05 \\
(0.0003)\end{array}$ & $\begin{array}{l}-0.0001 \\
(0.0002)\end{array}$ & $\begin{array}{c}0.0032 \\
(0.0076)\end{array}$ \\
\hline Malaria ecology $*$ Time trend & & $\begin{array}{c}0.0653 \\
(0.0605)\end{array}$ & & $\begin{array}{l}0.123^{* *} \\
(0.0566)\end{array}$ \\
\hline Malaria ecology $*$ Time trend ${ }^{2}$ & & $\begin{array}{l}-0.0033 \\
(0.0040)\end{array}$ & & $\begin{array}{l}-0.0070^{*} \\
(0.0037)\end{array}$ \\
\hline Observations & 88,316 & 88,316 & 88,316 & 356 \\
\hline $\begin{array}{l}\text { R-squared } \\
\text { Number of (split) regions }\end{array}$ & 0.016 & 0.276 & 0.412 & $\begin{array}{c}0.878 \\
136\end{array}$ \\
\hline Average Xs & & Yes & & \\
\hline Region FE & & Yes & & Yes \\
\hline Time trend & & Yes & & Yes \\
\hline Time trend ${ }^{2}$ & & Yes & & Yes \\
\hline Country FE $\times$ Time trend & & Yes & & Yes \\
\hline Country FE $\times$ Time trend ${ }^{2}$ & & Yes & & Yes \\
\hline Survey type FE & & Yes & & Yes \\
\hline Cluster FE & & & Yes & \\
\hline
\end{tabular}

Notes. "Average Xs" include average age, secondary education, household size, and wealth in the region. Robust standard errors, which are clustered by (split) region, are reported in parentheses.

*** denotes significance at $1 \%$ level. ** denotes significance at $5 \%$ level. * denotes significance at $10 \%$ level. 
Table V. Social multipliers

\begin{tabular}{lcccc}
\hline & $\begin{array}{c}\text { Sleeping } \\
\text { under any type } \\
\text { of bednet }\end{array}$ & $\begin{array}{c}\text { Sleeping } \\
\text { under } \\
\text { an ITN }\end{array}$ & $\begin{array}{c}\text { One dose } \\
\text { of Fansidar } \\
\text { or more }\end{array}$ & $\begin{array}{c}\text { Two doses } \\
\text { of Fansidar } \\
\text { or more }\end{array}$ \\
\hline Mother's or woman's & 2.364 & 1.715 & 9.243 & 6.161 \\
secondary education & $(0.449)$ & $(0.549)$ & $(2.229)$ & $(2.826)$ \\
& {$[1.742,3.353]$} & {$[0.703,2.793]$} & {$[7.302,14.435]$} & {$[2.609,16.369]$} \\
Household wealth & 2.159 & 0.861 & 8.701 & 10.413 \\
& $(0.444)$ & $(0.493)$ & $(3.614)$ & $(29.360)$ \\
& {$[1.273,3.009]$} & {$[-0.309,1.710]$} & {$[4.296,18.791]$} & {$[3.186,49.365]$} \\
\hline
\end{tabular}

Notes. The multipliers are computed using the individual-level models that control for cluster fixed effects and the regional-level models. We bootstrap the standard errors and confidence intervals of the social multipliers, applying a panel bootstrap using 1,000 replications. The standard errors of the social multipliers are reported in paretheses. The $95 \%$ bias-corrected confidence intervals of the social multipliers are reported in brackets. 
Table VI. Regional-level regressions for preventive behaviors for children (OLS and splitsample IV)

\begin{tabular}{lcc}
\hline & $\begin{array}{c}\text { Regional } \\
\text { OLS } \\
(1)\end{array}$ & $\begin{array}{c}\text { Regional } \\
\text { SSIV } \\
(2)\end{array}$ \\
\hline Panel A. Dependent variable: Sleeping under any & type of bednet \\
& $0.127^{* *}$ & $0.1551^{* *}$ \\
Mother's secondary education & $(0.0609)$ & $(0.0638)$ \\
& 0.0446 & 0.0403 \\
Household wealth & $(0.0334)$ & $(0.0329)$ \\
& & \\
Observations & 1,436 & 1,436 \\
R-squared & 0.754 & 0.882 \\
Number of (split) regions & 472 & 472 \\
First stage F-stat for education [P-value] & & $650.31[0.0000]$ \\
First stage F-stat for wealth [P-value] & & $4920.48[0.0000]$ \\
Kleibergen-Paap Wald F-stat & & 199.61
\end{tabular}

Panel B. Dependent variable: Sleeping under an ITN

Mother's secondary education

$\begin{array}{cc}0.0810 & 0.0748 \\ (0.0572) & (0.0602) \\ 0.0095 & 0.0173 \\ (0.0327) & (0.0337)\end{array}$

Household wealth

$\begin{array}{cc}1,342 & 1,342 \\ 0.815 & 0.874 \\ 430 & 430 \\ & 673.78[0.0000] \\ & 3838.72[0.0000]\end{array}$

R-squared

Number of (split) regions

$3838.72[0.0000]$

First stage F-stat for wealth [P-value]

237.13

Panel C. Dependent variable: One dose of Fansidar or more

Secondary education

Household wealth

Observations

R-squared

Number of (split) regions

First stage F-stat for education [P-value]

First stage F-stat for wealth [P-value]

Kleibergen-Paap Wald F-stat

$\begin{array}{cc}0.469^{* *} & 0.5012^{* *} \\ (0.215) & (0.2363) \\ 0.124^{*} & 0.1758^{*} \\ (0.0678) & (0.0650)\end{array}$

$\begin{array}{cc}388 & 388 \\ 0.901 & 0.959 \\ 146 & 146 \\ & 68.32[0.0000] \\ & 403.25[0.0000]\end{array}$

66.41

Panel D. Dependent variable: Two doses of Fansidar or more

Secondary education

Household wealth

Observations

R-squared

Number of (split) regions

First stage $\mathrm{F}$-stat for education [P-value]

First stage F-stat for wealth [P-value]

Kleibergen-Paap Wald F-stat

Region FE

Time trend

Time trend ${ }^{2}$

Country FE $\times$ Time trend

Country FE $\times$ Time trend ${ }^{2}$

Survey type FE

$\begin{array}{cc}0.206 & 0.2017 \\ (0.206) & (0.1691) \\ 0.0851 & 0.1014^{*} \\ (0.0547) & (0.0546)\end{array}$

\begin{tabular}{cc}
356 & 356 \\
0.878 & 0.945 \\
136 & 136 \\
& $33.38[0.0000]$ \\
& $558.47[0.0000]$ \\
& 33.63 \\
& \\
Yes & Yes \\
Yes & Yes \\
Yes & Yes \\
Yes & Yes \\
Yes & Yes \\
Yes & Yes \\
\hline
\end{tabular}

Notes. Split-sample estimates to correct for sampling error in education and wealth in regional models. Robust standard errors, which are clustered by (split) region, are reported in parentheses.

$* * *$ denotes significance at $1 \%$ level. ${ }^{* *}$ denotes significance at $5 \%$ level. ${ }^{*}$ denotes significance at $10 \%$ level. 


\section{Online Appendix A}

Table A.I. Variables used

\begin{tabular}{lcccc}
\hline & DHS, MIS, & MICS & MICS & MICS \\
Label & AIS & Wave 2 & Wave 3 & Wave 4 \\
\hline Sleeping under any type of bednet & hv228, v460, hml12 & ml8 & ml10 & tn11 \\
Sleeping under an ITN & hml12, hml19, ml0 & ml9 & ml12, ml13, ml14 & tn5 \\
Taking Fansidar & m49a & Not available & mn6* & mn14a \\
No. of doses of Fansidar & ml1 & Not available & mn6d & mn16 \\
Child is male & hv104, b4 & hl3 & hl4 & hl4 \\
Child age & hv105, b8 & hl4 & hl5 & hl6 \\
Mother/Woman's age & hv105, v012 & wi3b, memage, hl4, age & wm9, hl5 & wb2, hl6 \\
Mother/Woman's education & hc61, v106 & melevel & melevel & melevel \\
Water & hv201 & ws1 & ws1 & ws1 \\
Sanitation & hv205 & ws3 & ws7 & ws8 \\
Urban residence & hv025 & hi6 & hh6 & hh6 \\
Cluster & hv024, v024 & wiclno, chclno, hi1 & hh1 & hh1 \\
Region & hv007, v007 & hi7 & hh7 & hh7 \\
Year & & hi3y & hh5y \\
\hline
\end{tabular}

Notes. This table contains the "general" variables that we use in the analysis. Note that for some countries, we additionally use country-specific variables. For many countries, the region variable is country-specific. 


\section{Online Appendix B}

Table B.I. Regression to predict the malaria ecology index

\begin{tabular}{|c|c|c|c|}
\hline & & \multicolumn{2}{|c|}{ PfPR } \\
\hline & & Coeff. & S.e. \\
\hline Minimum precipitation & & $-0.0140^{* * *}$ & $(0.0050)$ \\
\hline- & square & $0.0007^{*}$ & $(0.0004)$ \\
\hline- & cube & $-1.44 \mathrm{e}-05$ & $(1.14 \mathrm{e}-05)$ \\
\hline- & quartic & $8.77 \mathrm{e}-08$ & $(9.21 \mathrm{e}-08)$ \\
\hline Average precipitation & & $0.0139^{* *}$ & $(0.0058)$ \\
\hline- & square & $-9.83 e-05$ & $(7.04 \mathrm{e}-05)$ \\
\hline- & cube & $4.66 \mathrm{e}-07$ & $(3.67 \mathrm{e}-07)$ \\
\hline- & quartic & $-8.20 \mathrm{e}-10$ & $(6.86 \mathrm{e}-10)$ \\
\hline Maximum precipitation & & $-0.0052^{* *}$ & $(0.0021)$ \\
\hline- & square & $3.02 \mathrm{e}-05^{* * *}$ & $(9.79 \mathrm{e}-06)$ \\
\hline- & cube & $-7.15 \mathrm{e}-08^{* * *}$ & $(1.94 \mathrm{e}-08)$ \\
\hline- & quartic & $5.24 \mathrm{e}-11^{* * *}$ & $(0)$ \\
\hline Minimum temperature & & -0.123 & $(0.772)$ \\
\hline- & square & 0.0243 & $(0.0629)$ \\
\hline- & cube & -0.0013 & $(0.0022)$ \\
\hline- & quartic & $2.18 \mathrm{e}-05$ & $(2.91 \mathrm{e}-05)$ \\
\hline Average temperature & & $-21.63^{* * *}$ & $(4.707)$ \\
\hline- & square & $1.353^{* * *}$ & $(0.302)$ \\
\hline- & cube & $-0.0373^{* * *}$ & $(0.0085)$ \\
\hline- & quartic & $0.0003^{* * *}$ & $(8.95 \mathrm{e}-05)$ \\
\hline Maximum temperature & & $12.25^{* * *}$ & $(2.884)$ \\
\hline- & square & $-0.661^{* * *}$ & $(0.159)$ \\
\hline- & cube & $0.0158^{* * *}$ & $(0.0038)$ \\
\hline- & quartic & $-0.0001^{* * *}$ & $(3.48 \mathrm{e}-05)$ \\
\hline Constant & & $43.50^{* *}$ & $(19.46)$ \\
\hline Observations & & 399 & \\
\hline R-squared & & 0.636 & \\
\hline
\end{tabular}

Notes. In this table, the observation is the (unsplit) region. The table presents the results of the regression of PfPR in the region on a number of precipitation and temperature variables in the same regino, in a very nonlinear setting. Our malaria ecology index is the linear prediction from this regression.

Here the sample contains 399 (unsplit) regions. Note that this number of regions (399) is larger than the number of (unsplit) regions used in the rest of the paper (340 - See Table I). Indeed, here we use all the available countries from Sub-Saharan Africa, with information on PfPR, precipitation and temperature, to run the regression above and get a very general malaria ecology index. Some of the countries we use here (Comoros, Equatorial Guinea, Guinea Bissau, Somalia, South Africa, and Sudan) do not have usable DHS/MIS/AIS/MICS data, and consequently cannot be used in the rest of the paper.

Standard errors are reported in parentheses.

*** denotes significance at $1 \%$ level. ** denotes significance at $5 \%$ level. $*$ denotes significance at $10 \%$ level. 


\section{Online Appendix C}

We here relax the assumption that survey fixed effects, region fixed effects, countryspecific time trends, malaria ecology interacted with time trends, and precipitation and temperature deviations completely address the endogeneity of $\bar{X}_{g t}$ in equation (7).

Assume that after controlling for all these variables, there is still a $v_{g t}^{*}$ that is correlated with $\bar{X}_{g t}$. Our strategy to address endogeneity takes the first difference of equation (7) and applies a GMM/IV estimator. Because different countries have surveys in different years, our first differences will not be with respect to the previous calendar year, but with respect to the previous survey year which will be different by country. Specifically, our transformation is given by

$$
\begin{aligned}
\bar{P}_{g t_{l, c}}-\bar{P}_{g t_{l-1, c}}= & {\left[\bar{X}_{g t_{l, c}}-\bar{X}_{g t_{l-1, c}}\right]\left(\frac{\beta+\delta}{1-\gamma}\right) } \\
& +\frac{\theta_{1}\left(Z_{1 c t_{l, c}}-Z_{1 c t_{l-1, c}}\right)}{1-\gamma}+\frac{\theta_{2}\left(Z_{2 g t_{l, c}}-Z_{2 g t_{l-1, c}}\right)}{1-\gamma} \\
& +\frac{v_{g t_{l, c}}^{*}-v_{g t_{l-1, c}}^{*}}{1-\gamma}+\left(\bar{\varepsilon}_{g t_{l, c}}^{\prime}-\bar{\varepsilon}_{g t_{l-1, c}}^{\prime}\right)
\end{aligned}
$$

This transformation eliminates the time-invariant component $v_{g}$, but $v_{g t_{l, c}}^{*}-v_{g t_{l-1, c}}^{*}$ will still be correlated with $\left[\bar{X}_{g t_{l, c}}-\bar{X}_{g t_{l-1, c}}\right]$ by definition. To obtain consistent estimates of $\frac{\beta+\delta}{1-\gamma}$, we apply instrumental variables to this equation, using the lags $\bar{X}_{g t_{l-2, c}}$ as instruments for $\left[\bar{X}_{g t_{l, c}}-\bar{X}_{g t_{l-1, c}}\right]$. The main limitations of this approach is that it can only be implemented for countries for which we have at least three waves of data and that the lags $\bar{X}_{g t_{l-2, c}}$ are likely to be a weak instrument for $\left[\bar{X}_{g t_{l, c}}-\bar{X}_{g t_{l-1, c}}\right]$.

Table C.I presents the results of the GMM/IV approach for children's preventive behaviors (in column (2)). The estimates are unreliable because of weak instruments (see the low value of the first-stage F-statistics).

We do not provide the results of the GMM/IV method for women's preventive behaviors because the regional-level sample with three waves of data is too small. 
Table C.I. Regional-level regressions (OLS and GMM/IV)

\begin{tabular}{|c|c|c|}
\hline & $\begin{array}{c}\text { Regional } \\
\text { OLS } \\
(1)\end{array}$ & $\begin{array}{c}\text { Regional } \\
\text { GMM/IV } \\
(2)\end{array}$ \\
\hline \multicolumn{3}{|c|}{ Panel A. Dependent variable: Sleeping under any type of bednet } \\
\hline Mother's secondary education & $\begin{array}{c}0.127^{* *} \\
(0.0609)\end{array}$ & $\begin{array}{c}-3.9056 \\
(22.8540)\end{array}$ \\
\hline Household wealth & $\begin{array}{c}0.0446 \\
(0.0334)\end{array}$ & $\begin{array}{c}0.8832 \\
(3.6296)\end{array}$ \\
\hline $\begin{array}{l}\text { Observations } \\
\text { R-squared } \\
\text { Number of (split) regions } \\
\text { First stage F-stat for education [P-value] } \\
\text { First stage F-stat for wealth [P-value] } \\
\text { Kleibergen-Paap Wald F-stat }\end{array}$ & $\begin{array}{c}1,436 \\
0.754 \\
472\end{array}$ & $\begin{array}{c}492 \\
-6.016 \\
302 \\
3.58[0.0144] \\
1.21[0.3057] \\
0.0100\end{array}$ \\
\hline \multicolumn{3}{|c|}{ Panel B. Dependent variable: Sleeping under an ITN } \\
\hline Mother's secondary education & $\begin{array}{c}0.0810 \\
(0.0572)\end{array}$ & $\begin{array}{l}-0.9385 \\
(3.9133)\end{array}$ \\
\hline Household wealth & $\begin{array}{c}0.0095 \\
(0.0327)\end{array}$ & $\begin{array}{c}1.2718 \\
(0.9006)\end{array}$ \\
\hline Observations & 1,342 & 482 \\
\hline R-squared & 0.815 & -0.188 \\
\hline Number of (split) regions & 430 & 293 \\
\hline First stage F-stat for education [P-value] & & $4.02[0.0080]$ \\
\hline First stage F-stat for wealth [P-value] & & $1.17[0.3216]$ \\
\hline Kleibergen-Paap Wald F-stat & & 0.04 \\
\hline Region FE & Yes & Yes \\
\hline Time trend & Yes & Yes \\
\hline Time trend ${ }^{2}$ & Yes & Yes \\
\hline Country FE $\times$ Time trend & Yes & Yes \\
\hline Country FE $\times$ Time trend ${ }^{2}$ & Yes & Yes \\
\hline Survey type FE & Yes & Yes \\
\hline
\end{tabular}

Notes. GMM/IV estimates to address the endogeneity of education and wealth in regional models.

Robust standard errors, which are clustered by (split) region, are reported in parentheses. *** denotes significance at $1 \%$ level. ${ }^{* *}$ denotes significance at $5 \%$ level. ${ }^{*}$ denotes significance at $10 \%$ level. 
Online Appendix D

Table D.I. Models controlling for wealth inequality

\begin{tabular}{lcc}
\hline & $\begin{array}{c}\text { Individual } \\
\text { OLS } \\
\text { Panel A. Dependent variable: }\end{array}$ & $\begin{array}{c}\text { Regional } \\
\text { OLS } \\
(1)\end{array}$ \\
Mother's secondary education & \multicolumn{2}{c}{$(2)$} \\
Household wealth & $\left(0.0043^{* * *}\right.$ & $0.118^{*}$ \\
& $0.0226^{* * *}$ & $(0.0605)$ \\
S.d. of household wealth & $(0.0021)$ & 0.0365 \\
& & $(0.0377)$ \\
Observations & & -0.0311 \\
R-squared & 662,105 & $(0.0561)$ \\
Number of (split) regions & 0.385 & 1,436 \\
& & 0.754 \\
\end{tabular}

Panel B. Dependent variable: Sleeping under an ITN

$\begin{array}{lcc}\text { Mother's secondary education } & 0.0451^{* * *} & 0.0781 \\ & (0.0035) & (0.0571) \\ \text { Household wealth } & 0.0179^{* * *} & 0.0091 \\ & (0.0021) & (0.0360) \\ \text { S.d. of household wealth } & & -0.0124 \\ & & (0.0565) \\ \text { Observations } & 601,031 & 1,342 \\ \text { R-squared } & 0.396 & 0.814 \\ \text { Number of (split) regions } & & 430\end{array}$

Panel C. Dependent variable: One dose of Fansidar or more

$\begin{array}{lcc}\text { Mother's secondary education } & 0.0507^{* * *} & 0.445^{* *} \\ & (0.0067) & (0.208) \\ \text { Household wealth } & 0.0143^{* * *} & 0.0930 \\ & (0.0047) & (0.0681) \\ \text { S.d. of household wealth } & & -0.187^{*} \\ & & (0.103) \\ \text { Observations } & 95,555 & 388 \\ \text { R-squared } & 0.580 & 0.903 \\ \text { Number of (split) regions } & & 146\end{array}$

Panel D. Dependent variabke: Two doses of Fansidar or more

\begin{tabular}{lcc} 
Mother's secondary education & $0.0334^{* * *}$ & 0.198 \\
& $(0.0057)$ & $(0.204)$ \\
Household wealth & $0.0081^{*}$ & 0.0736 \\
& $(0.0048)$ & $(0.0558)$ \\
S.d. of household wealth & & -0.0781 \\
& & $(0.0852)$ \\
Observations & 88,316 & 356 \\
R-squared & 0.412 & 0.878 \\
Number of (split) regions & & 136 \\
Cluster FE & Yes & \\
Region FE & & Yes \\
Time trend & & Yes \\
Time trend & & Yes \\
Country FE $\times$ Time trend & & Yes \\
Country FE $\times$ Time trend & & Yes \\
Survey type FE & & Yes \\
\hline
\end{tabular}

Notes. The same controls as in Table III and IV are included.

Robust standard errors, which are clustered by (split) region, are reported in parentheses.

*** denotes significance at $1 \%$ level. $* *$ denotes significance at $5 \%$ level. $*$ denotes significance at $10 \%$ level. 


\section{Online Appendix E}

Our analysis in Section 6 has investigated social interactions for Sub-Saharan Africa as a whole. However, one may expect differences in the level of social interactions between East and West Africa, since West Africans are much more tribalists than East Africans, historically at least (we thank Michael Darden for this suggestion). To examine that point, we break down our sample into Eastern and Western countries, and re-estimate the individual- and regional-level models separately for the two samples. In our list of countries, the countries in West Africa are the following: Mali, Burkina Faso, Niger, Benin, Côte d'Ivoire, Gambia, Ghana, Liberia, Senegal, Sierra Leone, Togo, and Nigeria, whereas the countries in East Africa are the following: Tanzania, Kenya, Uganda, Rwanda, Burundi, Ethiopia, Mozambique, Madagascar, Malawi, Zambia, and Zimbabwe. These list follow the United Nations scheme of geographic regions. Note that Angola, Cameroon, Central African Republic, Chad, and the Democratic Republic of the Congo, which are in Middle Africa according to the UN, are not separately analyzed because the number of observations is too small. Namibia and Swaziland, which are part of Southern Africa, are not analyzed either, because they also represent too few observations in our sample.

The results of the analysis are presented in Table E.I. Panels A and B report the results for children's preventive behaviors. The coefficients imply that for sleeping under any type of bednet, the social multiplier associated with the mother's education is larger than one in East Africa, whereas the social multiplier associated with household wealth is larger than one in West Africa. For sleeping under a treated net, the multiplier on household wealth is also larger than one in West Africa.

Panels C and D contain the estimates for women's preventive behaviors. For taking one dose of Fansidar or more, the social multiplier associated with education is greater than one in West Africa. 
Table E.I. Main model for East and West Africa

\begin{tabular}{ccccc}
\hline Individual & Regional & Individual & Regional \\
OLS & OLS & OLS & OLS \\
$(1)$ & $(2)$ & $(3)$ & $(4)$ \\
\hline \multicolumn{2}{c}{ East Africa } & \multicolumn{2}{c}{ West Africa }
\end{tabular}

Panel A. Dependent variable: Sleeping under any type of bednet

$\begin{array}{lcccc}\text { Mother's secondary education } & 0.0932^{* * *} & 0.227^{* *} & 0.0305^{* * *} & -0.117 \\ & (0.0073) & (0.0966) & (0.0040) & (0.105) \\ \text { Household wealth } & 0.0232^{* * *} & 0.0012 & 0.0214^{* * *} & 0.0838^{*} \\ & (0.0032) & (0.0599) & (0.0033) & (0.0474) \\ & & & & \\ \text { Observations } & 254,078 & 545 & 297,542 & 627 \\ \text { R-squared } & 0.407 & 0.832 & 0.346 & 0.698 \\ \text { Number of (split) regions } & & 168 & & 202\end{array}$

Panel B. Dependent variable: Sleeping under an ITN

$\begin{array}{lcccc}\text { Mother's secondary education } & 0.0760^{* * *} & 0.116 & 0.0265^{* * *} & -0.0402 \\ & (0.0062) & (0.0911) & (0.0035) & (0.110) \\ \text { Household wealth } & 0.0196^{* * *} & -0.0552 & 0.0169^{* * *} & 0.0888^{*} \\ & (0.0031) & (0.0570) & (0.0038) & (0.0456) \\ & & & & \\ \text { Observations } & 250,351 & 536 & 250,571 & 572 \\ \text { R-squared } & 0.410 & 0.868 & 0.361 & 0.805 \\ \text { Number of (split) regions } & & 168 & & 175\end{array}$

Panel C. Dependent variable: One dose of Fansidar or more

$\begin{array}{lcccc}\text { Secondary education } & 0.0585^{* * *} & 0.131 & 0.0300^{* * *} & 0.972^{* *} \\ & (0.0084) & (0.226) & (0.0084) & (0.442) \\ \text { Household wealth } & 0.0105^{*} & 0.106 & 0.0212^{* *} & 0.0952 \\ & (0.0053) & (0.112) & (0.0084) & (0.0753) \\ \text { Observations } & 54,021 & 244 & 38,043 & 126 \\ \text { R-squared } & 0.554 & 0.895 & 0.614 & 0.952 \\ \text { Number of (split) regions } & & 86 & & 51\end{array}$

Panel D. Dependent variable: Two doses of Fansidar or more

\begin{tabular}{|c|c|c|c|c|}
\hline Secondary education & $\begin{array}{c}0.0354^{* * *} \\
(0.0067)\end{array}$ & $\begin{array}{c}0.0220 \\
(0.216)\end{array}$ & $\begin{array}{c}0.0248^{* *} \\
(0.0119)\end{array}$ & $\begin{array}{c}0.503 \\
(0.538)\end{array}$ \\
\hline Household wealth & $\begin{array}{c}0.0059 \\
(0.0051)\end{array}$ & $\begin{array}{c}0.117 \\
(0.0794)\end{array}$ & $\begin{array}{c}0.0120 \\
(0.0087)\end{array}$ & $\begin{array}{c}0.0214 \\
(0.0755)\end{array}$ \\
\hline Observations & 47,286 & 212 & 37,558 & 126 \\
\hline R-squared & 0.394 & 0.892 & 0.421 & 0.891 \\
\hline Number of (split) regions & & 76 & & 51 \\
\hline Cluster FE & Yes & & Yes & \\
\hline Region FE & & Yes & & Yes \\
\hline Time trend & & Yes & & Yes \\
\hline Time trend ${ }^{2}$ & & Yes & & Yes \\
\hline Country FE $\times$ Time trend & & Yes & & Yes \\
\hline Country FE $\times$ Time trend ${ }^{2}$ & & Yes & & Yes \\
\hline Survey type FE & & Yes & & Yes \\
\hline
\end{tabular}

Notes. The same controls as in Table III and IV are included.

Robust standard errors, which are clustered by (split) region, are reported in parentheses.

*** denotes significance at $1 \%$ level. ** denotes significance at $5 \%$ level. ${ }^{*}$ denotes significance at $10 \%$ level. 


\section{Online Appendix F}

Table F.I. Excess variance across groups and social interactions

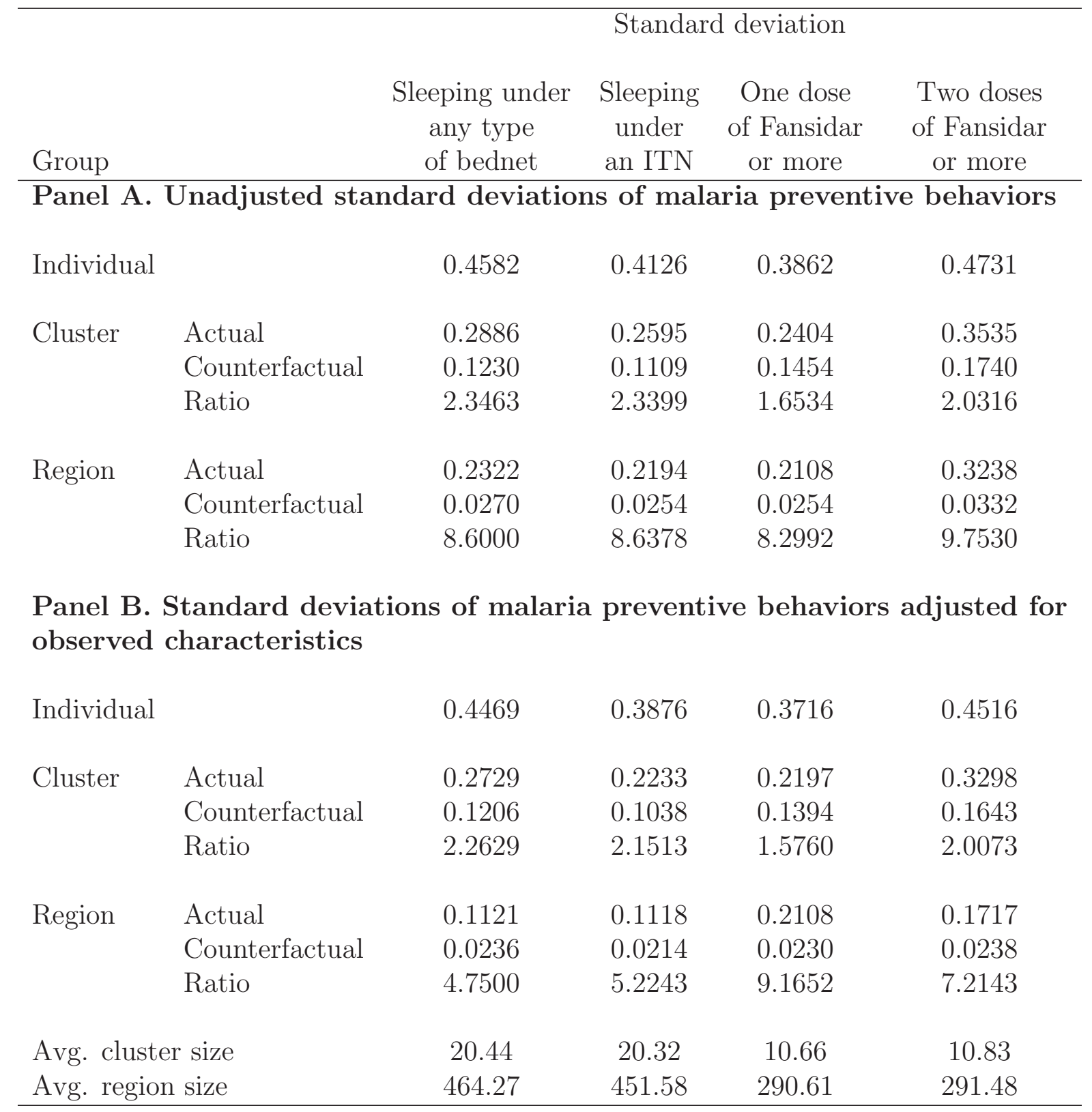

